\title{
Comparative analysis of the fragility curves for Italian residential masonry and RC buildings
}

\author{
Francesca da Porto ${ }^{1} \cdot$ Marco Donà ${ }^{1}$ (D) - Annalisa Rosti ${ }^{2} \cdot$ Maria Rota $^{3}$. \\ Sergio Lagomarsino ${ }^{4}$. Serena Cattari ${ }^{4}$ - Barbara Borzi ${ }^{3} \cdot$ Mauro Onida $^{3}$. \\ Daniela De Gregorio ${ }^{5}$. Francesca Linda Perelli ${ }^{5}$. Carlo Del Gaudio ${ }^{6}$. Paolo Ricci ${ }^{6}$. \\ Elena Speranza ${ }^{7}$
}

Received: 31 October 2020 / Accepted: 5 May 2021 / Published online: 26 May 2021

(c) The Author(s) 2021

\begin{abstract}
The Department of Civil Protection (DPC), in compliance with the EU decision 1313/2013 and at the request of the Sendai Framework for Disaster Risk Reduction 2015-2030 to update the disaster risk assessments by various countries, released the latest National Risk Assessment for Italy at the end of 2018. Specifically, as regards the seismic risk assessment, six research units belonging to two centres of competence of the DPC collaborated under its guidance to update the risk maps of the Italian residential heritage. This extensive collaboration complied with the recent Italian code for Civil Protection, which requires a broad scientific consensus for risk assessment. During this research activity, six fragility models were developed, according to some common criteria (four for masonry buildings and two for RC buildings). These models were then implemented by the DPC for the definition of the national seismic risk. Within this context, the aim of this paper is to evaluate the risk results provided by these models, compare their features, and assess and validate their prediction capabilities. In particular, this paper shows the comparison of predicted and observed damage scenarios and consequences on building stock and the population of two seismic events, i.e. L'Aquila 2009 and Amatrice 2016. Furthermore, the paper provides some interesting damage and risk predictions at a national level. Overall, the forecasts and comparisons made in this study demonstrate the validity of the approach adopted by the DPC for the assessment of national seismic risk.
\end{abstract}

Keywords Residential buildings $\cdot$ Seismic vulnerability $\cdot$ Fragility models $\cdot$ Seismic damage scenarios $\cdot$ Economic losses $\cdot$ Casualties $\cdot$ Homeless

Marco Donà

marco.dona.1@unipd.it

Extended author information available on the last page of the article 


\section{Introduction}

\subsection{Goals, methodology and tools of the study}

The Department of Civil Protection (DPC) released the latest National Risk Assessment for Italy at the end of 2018 (ICPD 2018), in response to the EU decision 1313/2013 and in line with the requirements of the Sendai Framework for Disaster Risk Reduction 2015-2030 (United Nations 2015). According to the recent code for Civil Protection (Legislative Decree no. 1, 2018), the National Risk Assessment for Italy (ICPD 2018) deals with the following eight natural risks: seismic, volcanic, tsunami-related, hydraulic, hydrogeological, adverse meteorological events, droughts and forest fires.

The same code for Civil Protection, in accordance with the first of four priority actions of the Sendai Framework ("Understanding Disaster Risk"), defines the knowledge of risk scenarios as an essential prevention activity. It also establishes that, in addition to having sound scientific bases, risk assessment should receive broad consensus from the scientific community. To comply with this, six research units belonging to two competence centres of the DPC, namely ReLUIS (Network of University Laboratories for Seismic Engineering) and EUCENTRE (European Center for Training and Research in Earthquake Engineering), collaborated under the guidance and coordination of DPC to update the seismic risk maps of the Italian residential heritage. To this end, and according to some common criteria, the six research units developed specific vulnerability/fragility models, which were subsequently implemented in the dedicated I.R.MA (Italian Risk MAps) platform, according to the methodology described in Dolce et al. (2020).

I.R.MA is a platform developed by EUCENTRE (Borzi et al. 2020a) to share data and models for the risk assessment of Italian residential buildings. It relies on the OpenQuake calculation engine (Pagani et al. 2014) to derive damage/risk maps-both conditional (associated with an event with a set return period) and unconditional (associated with the hazard in a given time window) — based on the hazard model MPS04 (Stucchi et al. 2004, 2011), and damage scenarios associated with preloaded ShakeMaps. In I.R.MA, the minimum calculation unit is the municipality, and the hazard and exposure information is associated with its centroid. In particular, the exposure data in I.R.MA is collected from the census of the Italian National Institute of Statistics (ISTAT, both the 2001 and 2011 censuses are preloaded), and are disaggregated by construction material, age of construction and number of storeys - the parameters which define the building typologies to which the fragility models refer to.

Four out of the six fragility models refer to masonry buildings, and the remaining two to RC buildings. Among the masonry fragility models, one has a mechanical derivation (Donà et al. 2020), one is based on an empirical-heuristic approach (Lagomarsino et al. 2021) and the other two have an empirical derivation (Rosti et al. 2020a; Zuccaro et al. 2020). Regarding the models for RC buildings, one is developed on a mechanical basis (Borzi et al. 2020b) and the other on an empirical basis (Rosti et al. 2020b). The criteria behind these models and the relevant state of art for their derivation is presented in the above-mentioned papers. In addition, a complete state of the art review on the methodological aspects of risk assessment is given by Dolce et al. (2020). For each material, these models were selected as they have been developed on the basis of different assumptions and strategies, and they were consolidated over the years by the various research units. A unique opportunity for calibration and validation of these models was provided by the availability of the recent Da.D.O. database (Observed Damage Database; Dolce et al. 2017, 
2019). This database is a web-gis platform that stores and shares data from extensive surveys on post-earthquake damage, carried out in the aftermath of the most significant Italian earthquakes from 1976 to 2013. Indeed, the empirical data remains the only tool to truly test the reliability of risk models (see also Riga et al. 2021).

The possibility of using conceptually different models represents a very positive aspect in order to obtain a risk assessment with broad scientific consensus. At the same time, this poses a clear challenge to the various authors, requiring a careful critical evaluation of the strengths and weaknesses of their models (and related derivation hypotheses), also in relation to the other models. In this context, the present work is motivated by the need to evaluate and compare the risk results provided by these fragility models, as they represent the basis of the national seismic risk update (ICPD 2018). To this end, the use of the I.R.MA platform was essential to produce objective comparisons, as the only variables of the study are represented by the vulnerability and fragility models. Moreover, these variables are all based on the EMS98 damage scale (Grünthal 1998).

The ultimate goal of this paper is the critical assessment of the prediction capabilities of these models in terms of damage estimates (conditional and unconditional) and other consequences (such as economic losses, unusable buildings, casualties, etc.), also in relation to their derivation hypotheses. Therefore, brief descriptions of the Italian residential building heritage, the fragility models used and the rules for evaluating earthquake losses and impacts are given. Subsequently, the paper presents the following comparisons: (1) predicted and observed damage scenarios and consequences on building stock and population for two seismic events, L'Aquila 2009 and Amatrice 2016 (for which a ShakeMap consistently derived with the INGV procedure is available), and (2) conditional and unconditional seismic damage and risk at national level. On the basis of these results, the effectiveness of the various fragility models is discussed. In addition, the paper provides some interesting risk predictions for Italy.

\subsection{Exposure of the Italian residential building heritage}

The fragility models described in Sect. 2 refer to building typologies defined on the basis of the relevant parameters available in the national census database, i.e. construction material, number of floors and construction age. In particular, according to the ISTAT 2001 census, $61 \%$ of Italian residential assets are made up of masonry (M) buildings and $25 \%$ of reinforced concrete (RC) buildings; the remaining minority share (14\%) is defined as "other" $(\mathrm{O})$ buildings, and refers to steel or wooden or mixed typology (generally $\mathrm{M}+\mathrm{RC}$ ) buildings, or even buildings for which there is no data available pertaining to the material they consist of. Considering the lower statistical significance of the " $O$ " category, the uncertainty about its material, and the fact that fragility models were developed only for $\mathrm{M}$ and $\mathrm{RC}$ buildings, the share of $\mathrm{O}$ was subdivided between $\mathrm{M}$ and $\mathrm{RC}$ buildings according to the criteria specified in DPC-Eucentre (2018). Specifically, buildings up to 5 storeys were all classified as M buildings when built before 1945 and, when built subsequently, they were subdivided between $\mathrm{M}$ and RC buildings based on the incidence of these in each municipality. Instead, buildings with more than 5 storeys were all assumed either as $\mathrm{M}$ buildings, if built before 1919, or as RC buildings otherwise.

Figure 1 shows the main information on Italian residential assets, based on the ISTAT (2001) census and is directly derived from IRMA; this is the reference exposure for the subsequent comparative damage/risk assessments at a national scale. As can be seen in the first row of graphs in Fig. 1, although masonry is quite prevalent in terms of building 


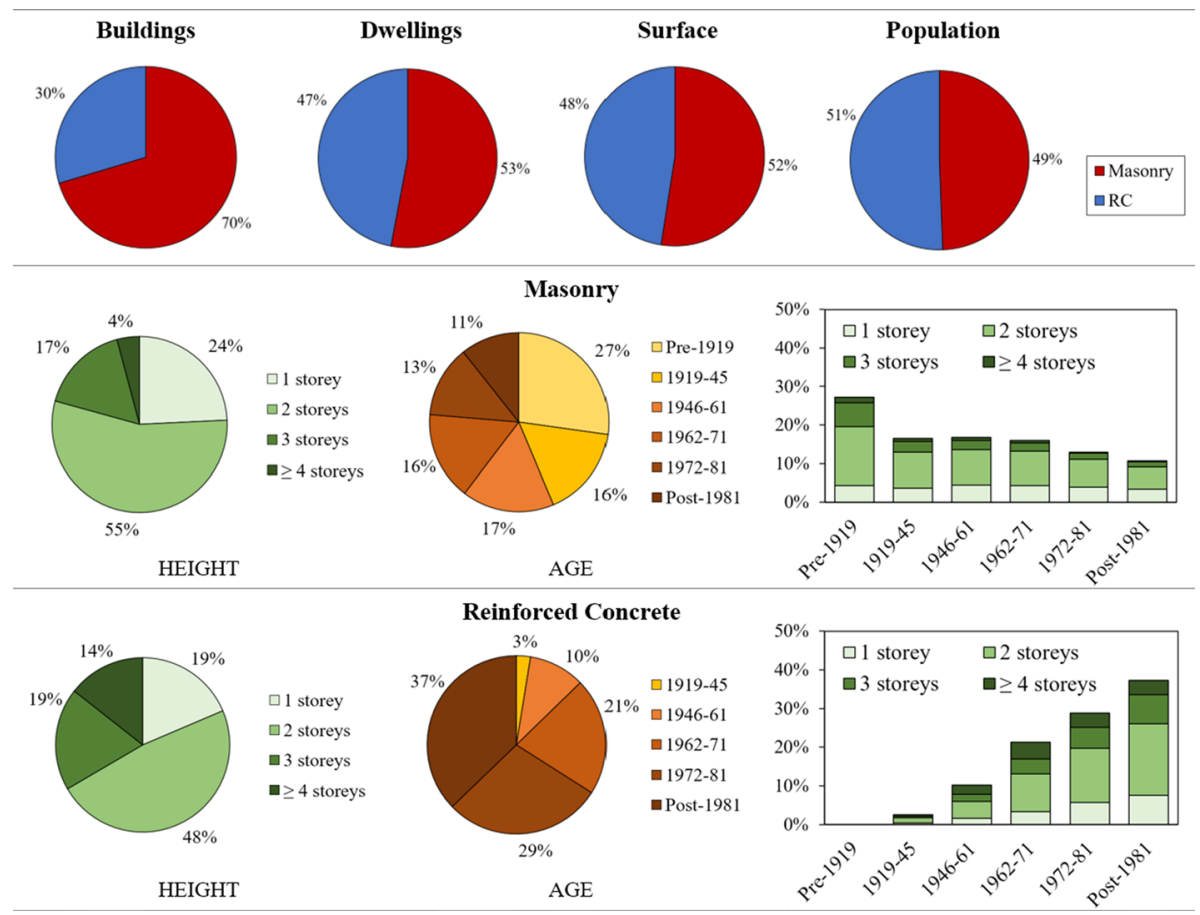

Fig. 1 Information on the exposure of the national residential heritage (according to ISTAT 2001)

material, RC and masonry are almost equivalent in terms of dwellings, floor surface and population (with slightly higher percentage values for RC structures). The main reason is that RC buildings generally have a higher number of storeys and, therefore, more housing units per building compared to $\mathrm{M}$ buildings, which mostly correspond to single dwellings. This is highlighted by the following graphs in Fig. 1, which show the subdivision of the buildings by number of storeys, age of construction and combination of the previous ones (according to the classes of ISTAT 2001), respectively for M and RC. These graphs also highlight that $\mathrm{M}$ buildings were built with fairly regular frequency over the years, whereas $\mathrm{RC}$ ones were built with increasing frequency.

Note that, although the 2011 census is available, the ISTAT 2001 dataset was used for the National Risk Assessment (ICPD 2018), as it is more detailed for some building characteristics (see Dolce et al. 2020).

\section{Fragility and impact/loss models}

\subsection{Fragility models for masonry buildings}

The main characteristics of the fragility models for Italian URM residential buildings, classified in ISTAT typologies on the basis of the construction age and the height class (see Table 1), are briefly reported below. 
Table 1 Summary of fragility models for residential masonry buildings

\begin{tabular}{lllll}
\hline Vulnerability model & General approach & Construction age & Building height \\
\hline Donà et al. (2020) & Mechanical & $<1919$ & $1962-1981$ & L: $1-2$ storeys \\
& & $1919-1945$ & $>1981$ & MH: $>2$ storeys \\
& & $1946-1961$ & & \\
Lagomarsino et al. (2021) & Empirical-heuristic & $<1919$ & $1962-1981$ & L: $1-2$ storeys \\
& & $1919-1945$ & $>1981$ & M: $3-5$ storeys \\
& & $1946-1961$ & & H: $>5$ storeys \\
Rosti et al. (2020a) & Empirical & $<1919$ & $1962-1971$ & L: $1-2$ storeys \\
& & $1919-1945$ & $1972-1981$ & MH: $>2$ storeys \\
& & $1946-1961$ & $>1981$ & \\
Zuccaro et al. (2020) & Empirical & $<1919$ & $1962-1971$ & L: $1-2$ storeys \\
& & $1919-1945$ & $1972-1981$ & M: $3-5$ storeys \\
& & $1946-1961$ & $>1981$ & H: $>5$ storeys \\
\hline
\end{tabular}

\subsubsection{Donà et al. (2020)}

The fragility model developed by the University of Padova is a mechanical model, based on the following derivation phases and hypotheses:

- Creation of a database of over 500 buildings (containing geometric-, material- and construction information), based on criteria of geographical and typological representativeness at a national level.

- Derivation of a mechanics-based seismic fragility model (Donà et al. 2019b), calibrated using the previous database and based on the Vulnus_4.0 software (Valluzzi et al. 2009), which evaluates the in-plane and out-of-plane mechanisms of URM buildings, returning the most likely and the Upper- and Lower-Bound fragilities corresponding to a damage DS2-3.

- Extension of the mechanical model on the whole EMS98 damage scale (from DS1 to DS5). This was done using an approach based on the fragility model proposed by Lagomarsino and Cattari (2014), the correlation law between macroseismic intensity $I$ and PGA according to Margottini et al. (1992), and the knowledge of the fragility interval, due to the various uncertanties at stake, defined by the Upper and LowerBound fragility curves.

\subsubsection{Lagomarsino et al. (2021)}

The fragility model developed by the University of Genova is an empirical-heuristic model, based on the following derivation phases and hypotheses:

- Revision of the macroseismic vulnerability model-originally proposed by Lagomarsino and Giovinazzi (2006) — based on the damage data available from the seismic events of Irpinia 1980 and L'Aquila 2009 (in the Da.D.O. database), which led to a reformulation of the macroseismic vulnerability curves as a function of the vulnerability $(V)$ and ductility $(Q)$ indices. 
- Analytical definition of the fragility curves (from DS1 to DS5) for the EMS98 vulnerability classes based on the mean damage level (function of index $V$ ) and on an I-PGA correlation law directly obtained from the INGV ShakeMap of L'Aquila 2009 (substantially in agreement with that proposed by Margottini et al. 1992; Faccioli and Cauzzi 2006).

- Calibration of the vulnerability index $V$ for the various ISTAT typologies and derivation of the exposure/vulnerability conversion matrix in which, for each ISTAT tipology, the percentage of buildings (that behave like each vulnerability class) is given. Key points of the calibration are the consideration of the observed mean damage state and the assumption of a binomial distribution of the DSs. In fact, the observed mean damage state is less sensitive than the single damage states (DSs) to incompleteness and errors of the field survey.

\subsubsection{Rosti et al. (2020a)}

The fragility model developed by the University of Pavia is an empirical model, based on the following derivation phases and hypotheses:

- Processing of post-earthquake damage data from the seismic events of Irpinia 1980 and L'Aquila 2009 (available in Da.D.O.), identifying the overall damage level of the building (from DS1 to DS5) on the basis of the maximum observed damage (Rosti et al. 2018) using the conversion rules proposed by Dolce et al. (2019) and Rota et al. (2008).

- Derivation of typological fragility curves for eight masonry building typologies (identified on the basis of the texture and quality of the masonry fabric, in-plane flexibility of the diaphragms and presence of ties), in terms of PGA (which values are derived from the INGV ShakeMaps).

- Merging of the empirical fragility curves thus obtained, approximated as logonormal and characterised by a single dispersion value for all DSs, in three vulnerability classes and two height classes based on the similarity of the observed fragility.

- Derivation of seismic fragility for the various ISTAT typologies as a linear combination of the fragility curves of the vulnerability classes.

\subsubsection{Zuccaro et al. (2020)}

The fragility model developed by PLINIVS is an empirical model, based on the following derivation phases and hypotheses:

- Processing of post-earthquake damage data (converted to EMS98 scale, from DS1 to DS5) corresponding to the seismic events of Irpinia 1980 and L'Aquila 2009. These data are available in the PLINIVS database (Zuccaro 2004) in relation to the PGA values obtained from the INGV ShakeMap of L'Aquila 2009 from the conversion of the intensity data of Irpinia 1980 according to Margottini et al. (1992).

- Definition of three vulnerability classes using the SAVE method (Zuccaro and Cacace 2015), a procedure which defines a correlation between the occurrence of a level of damage and the typological characteristics of damaged buildings.

- Calculation of the associated vulnerability curves through a regression method, which uses lognormal functions weighted on the level of data reliability for each PGA value 
[obtained from the L'Aquila 2009 dataset and extended to the Irpinia 1980 data (Perelli et al. 2019)].

- Derivation of seismic fragility for the various ISTAT typologies by assigning the vulnerability class according to an update of the BINC procedure (Cacace et al. 2018). This was based on statistical correlations between the surveyed building data (PLINIVS database) and the few relevant data of ISTAT.

\subsection{Fragility models for RC buildings}

The main characteristics of the fragility models for Italian RC residential buildings, classified in macro-typologies on the basis of vulnerability and height classes (see Table 2), are briefly reported below. In general, the vulnerability class C2 applies to RC buildings primarily designed for gravity loads, whereas the class D applies to seismically designed ones. The assignment of classes to buildings depends on their age of construction and year of seismic classification of the municipality to which they belong.

\subsubsection{Borzi et al. (2020b)}

The fragility model developed by EUCENTRE is a mechanical model, based on the following derivation phases and hypotheses:

- Definition of the sample of buildings through a Monte Carlo generation, starting from a representative building prototype for each building typology and varying predefined structural parameters according to a-priori probabilistic distributions.

- Application of the SP-BELA methodology (Borzi et al. 2008) to develop the vulnerability model, based on: (1) simulated design of the buildings, according to the code in place at the time of construction, (2) non-linear static analysis to define the associated equivalent single-degree-of-freedom (SDOF) systems, (3) evaluation of the exceedance probabilities of two DSs (severe damage and collapse), for various PGA values, comparing the displacement capacity and demand of the SDOF systems.

- Extensions of the fragility curves to all DSs of the EMS98 through calibrations based on comparisons between simulated and observed damage scenarios (using Da.D.O.). Hence, completion of the model for the classes of Table 2, with class $\mathrm{C} 2$ that includes all pre-1982 buildings, regardless of the year of seismic classification of the municipality.

- Derivation of the fragility of the ISTAT typologies as a linear combination of the fragility curves of the vulnerability classes.

Table 2 Summary of fragility models for residential RC buildings

\begin{tabular}{llll}
\hline Vulnerability model & General approach & Vulnerability class & Building height \\
\hline Borzi et al. (2020b) & Mechanical & C2 & $\begin{array}{c}\text { Single number of } \\
\text { storeys (from 1 } \\
\text { to 8) }\end{array}$ \\
& & D & L: 1-2 storeys \\
Rosti et al. (2020b) & Empirical & C2 $3-4$ storeys \\
& & D & H: $>4$ storeys \\
\hline
\end{tabular}




\subsubsection{Rosti et al. (2020b)}

The fragility model developed by the University of Pavia and the University of Naples Federico II is an empirical model, based on the following derivation phases and hypotheses:

- Processing of post-earthquake damage data from the seismic events of Irpinia 1980 and L'Aquila 2009 (available in Da.D.O.), identifying the overall damage level (from DS1 to DS5) according to the conversion rules proposed by Dolce et al. (2019) and by Rota et al. (2008) — for the structural components — and by Del Gaudio et al. (2017) — for the non-structural components, and taking the maximum of these as the damage level of the building.

- Integration of the damage database of the buildings belonging to completely (or almost) non-surveyed municipalities, as they provide a negative evidence of damage (DS0).

- Derivation of the fragility curves in terms of PGA (whose values derived from the ShakeMaps) for $15 \mathrm{RC}$ building typologies, defined by the number of storeys (1 to 5) and by three design levels (gravity loads only, seismic-before 1981 and seismic-after 1981).

- Converting these fragility curves (approximated as logonormal and with a single value of dispersion for all DSs) into fragility curves for the classes of Table 2, including in class C2 buildings designed for gravity loads only or seismically designed pre-1981, and in class D buildings seismically designed post-1981, based on the representativeness of each RC building typology evaluated at a national level.

- Derivation of the fragility of the ISTAT typologies as a linear combination of the fragility curves of the vulnerability classes.

\subsection{Loss and impact models}

As mentioned in the Introduction, the risk results obtained from the various fragility models are shown and compared in the following sections both in terms of damage estimates and consequences of the earthquake, i.e. direct economic losses, casualties (injury and death) and unusable buildings (in the short- and long-term).

To this end, the six research units involved in this work defined shared damage-toimpact models, reported in Tables 3, 4, 5. This allowed for the consistent evaluation of the impact of earthquakes, starting from the damage distribution estimated by each fragility model. These models, which apply to both masonry and RC buildings, albeit simplified, find on average a reasonable confirmation on the empirical data of recent Italian earthquakes (e.g., see Di Ludovico et al. 2017a, b), and were widely discussed and accepted by the entire working group coordinated by the DPC.

In particular, Table 3 provides the sets of coefficients which can be used to convert, through a weighted average, damage estimates into predictions of direct economic loss. The coefficients given in Table 3 are percentages of the reconstruction cost of residential buildings, which was assumed equal to $1350 € / \mathrm{m}^{2}$ (technical expenses and VAT included). This cost varies significantly based on the housing typology (i.e., public, medium and valuable housing), the type of structure and the geographical area (D'Alpaos and Bragolusi 2020). The assumed value, representative of medium housing and multi-storey buildings (e.g., see DEI price list, CIAM1563 2019), when multiplied by the total built area (about 2.5 billions $\mathrm{m}^{2}$ according to ISTAT 2001) leads to a total 
asset replacement cost for Italy of 3400 billion euros (Dolce et al. 2020). These figures are very close to the 3200 billion euros reported in the European exposure model (Crowley et al. 2020) and used by the Global Earthquake Model (GEM) Foundation (Silva et al. 2018, 2020). In Table 3, the "reference" set provides the cost parameters that can be used to calculate direct economic losses, calibrated to the actual repair costs of the reconstruction process following the recent Italian earthquakes (Di Ludovico et al. 2017a, b). It is also used for the National Risk Assessment (ICPD 2018, Dolce et al. 2020). Conversely, the "upper bound" set takes into account reconstruction strategies based on the "build back better" approach, which includes more complex measures (seismic improvement, energy efficiency upgrading, etc.), characterized by higher costs than those merely related to direct economic losses.

Table 4 shows the sets of coefficients to predict death and injury from damage-related estimates. These coefficients are given as percentage of the population involved in the risk assessment. There are several proposals on how to predict the number of victims after earthquakes. For example, the original idea of Coburn and Spence (1992) was further developed and updated by various authors. Updates were made both on the basis of information from significant earthquakes worldwide (e.g., Spence et al. 2011) and through calibrations in relation to local contexts (e.g., for Italy, see Zuccaro and Cacace 2011; Alexander 2011). In any case, the high uncertainty that characterises these estimates is emphasised in all the works due to the multiple factors that can influence the real impact (e.g. the presence of occupants at different times of the day and seasons of the year, the mechanisms of damage and collapse of buildings, the effectiveness of rescue operations, etc.). In this study, it was reasonably assumed that there is no death or injury for damage levels less than or equal to DS3.

Lastly, Table 5 shows the sets of coefficients to turn damage estimates into predictions of usable, unusable -in the short- and long-term- and collapsed buildings and dwellings. These coefficients are given as a percentage of buildings located in the risk simulation area.

Table 3 Damage-to-direct economic loss model

Table 4 Damage-to-human loss model

Table 5 Damage-to-building impact model

\begin{tabular}{llllll}
\hline \% of reconstruction cost & DS1 & DS2 & DS3 & DS4 & DS5 \\
\hline Reference set & 2 & 10 & 30 & 60 & 100 \\
Upper bound set & 5 & 20 & 45 & 80 & 100 \\
\hline
\end{tabular}

\begin{tabular}{llllll}
\hline \% of population & DS1 & DS2 & DS3 & DS4 & DS5 \\
\hline Deaths & 0 & 0 & 0 & 1 & 10 \\
Injured & 0 & 0 & 0 & 5 & 30 \\
\hline
\end{tabular}

\begin{tabular}{llllll}
\hline$\%$ of buildings/dwellings & DS1 & DS2 & DS3 & DS4 & DS5 \\
\hline Usable & 100 & 60 & 0 & 0 & 0 \\
Unusable (short period) & 0 & 40 & 40 & 0 & 0 \\
Unusable (long period) & 0 & 0 & 60 & 100 & 0 \\
Collapsed & 0 & 0 & 0 & 0 & 100 \\
\hline
\end{tabular}


To derive these coefficients, the data available in the Da.D.O. database were used, and other useful information can be found in Dolce and Di Bucci $(2017,2018)$.

\section{The L'Aquila seismic event (2009)}

\subsection{The 2009 L'Aquila earthquake}

A first comparison of the performance of the fragility models is proposed on the basis of the 2009 L'Aquila earthquake as it was one of the most devastating Italian events in recent years (magnitude moment $\mathrm{Mw}=6.3,309$ deaths, more than 1600 injured and nearly 70,000 displaced people). In addition, it is also the most suitable for validating the various models, for its thoroughness and reliability of corresponding information on observed damage and ground shaking.

The damage surveys following L'Aquila earthquake were based on the latest revision of the AeDES form (Baggio et al. 2007). This form requires the main information about the building (age, material, purpose of use, etc.) as well as the identification of the DSs and their extent $e$, with respect to the entire building - all the main structural and non-structural elements. Furthermore, the same form requires a final judgment on safety and usability, in relation to the observed damage. Although the damage metric is based on the EMS98 scale, the DSs are grouped as follows for expeditious survey purposes: DS0 (no damage), DS1 (slight), DS2-DS3 (moderate), DS4-DS5 (severe); as for the extent of damage, the metric is: $e<1 / 3,1 / 3<e<2 / 3, e>2 / 3$.

Through the AeDES form, information on building damage was widely detected in the area affected by the event, and is available in the Da.D.O. database (Dolce et al. 2019). Figure $2 \mathrm{a}$ shows the completeness ratio of the survey (i.e., the number of inspected buildings over the total number of buildings, retrieved from the national census) for all municipalities involved, whereas Fig. 2b shows the ShakeMap of the main event of 6 April 2009 (available on the INGV website).

In general, the incompleteness of the survey on the entire area affected by an earthquake is one of the main sources of uncertainty affecting the empirical data. Indeed, due to the aim of the surveys, this information decreases as it moves away from the epicentre, i.e. for

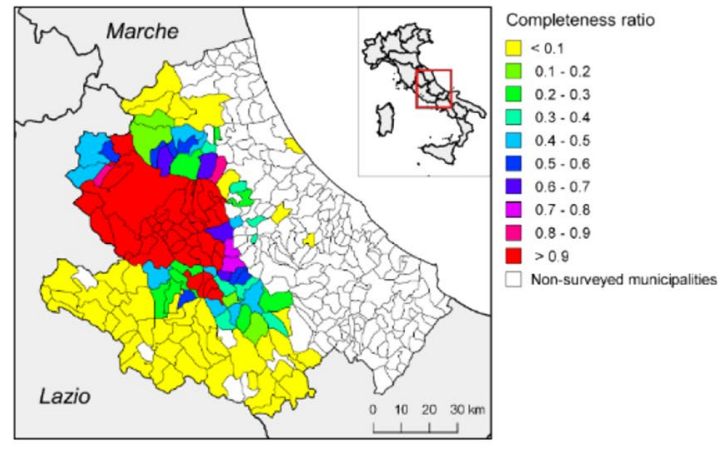

(a)

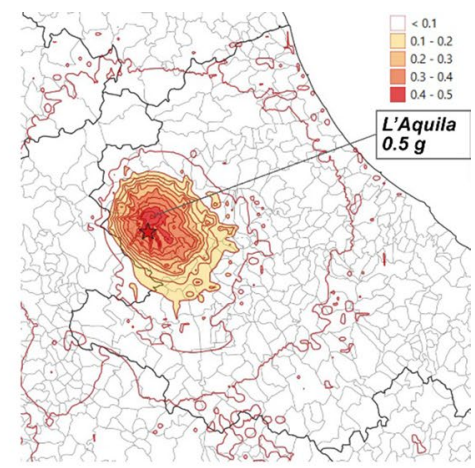

(b)

Fig. 2 Completeness ratio of the municipalities surveyed after the L'Aquila event a. ShakeMap of the main event, April 6, 2009 b 
the municipalities with lower PGA values, where it is very likely that damage surveys are limited to the specific requests of the owners. Consequently, the empirical damage distribution will be characterised by an underestimation of undamaged buildings (DS0), particularly for the low PGA range. To overcome this issue, some researchers assumed that noninspected buildings were undamaged (e.g. Karababa and Pomonis 2011; Eleftheriadou and Karabinis 2013), whereas others excluded municipalities with a percentage of inspected buildings below a certain completeness threshold from the damage assessment (e.g. Goretti and Di Pasquale 2004; Rota et al. 2008; Rosti et al. 2018). On one side, assuming that non-inspected buildings are undamaged may be questionable, particularly for the towns with intermediate completeness ratios and characterised by non negligible ground shaking. On the other hand, processing data only from municipalities that exceed a preselected completeness threshold reduces the number of suitable data, especially for less populated building typologies (Rossetto et al. 2013).

In this study, for the purpose of a comparison as objective as possible between observed and predicted damage scenarios, reference was made to a post-earthquake dataset based only on the 36 completely-surveyed municipalities, i.e., those with a completeness ratio larger than $90 \%$ (for a total of 36,750 buildings). A significant portion of the available empirical data derives from the L'Aquila municipality (completely surveyed), allowing for a robust and statistically representative damage dataset. In any case, the capability of the various fragility models to predict the damage distributions in the municipalities least affected by the ground shaking is also tested (see Sect. 3.3), by pooling together data from the non-surveyed and partially-surveyed (completeness ratio $<10 \%$ ) municipalities.

Figure 3 shows the distribution of masonry and RC buildings belonging to this database, according to the typological classes adopted by the fragility models (see Tables 1, 2). Figure 4 shows the global damage distribution of this masonry and RC buildings database, based on the rule proposed by Dolce et al. (2019) for converting the AeDES damage description into discrete EMS98 damage levels. In particular, this damage rule assigns a discrete damage level of the EMS98 scale to every possible combination of severity and extent of the observed damage, as reported in the AeDES form. The overall damage level for each building was then defined as the maximum damage observed on the vertical and horizontal structures and the roof for masonry buildings, and on the vertical structure and masonry infills/partitions for RC buildings. In the latter case, the conversion rule by Del Gaudio et al. (2017) was applied to convert the non-structural damage expressed, according to the AeDES form, into EMS98 damage levels. Specifically, this conversion rule assigns

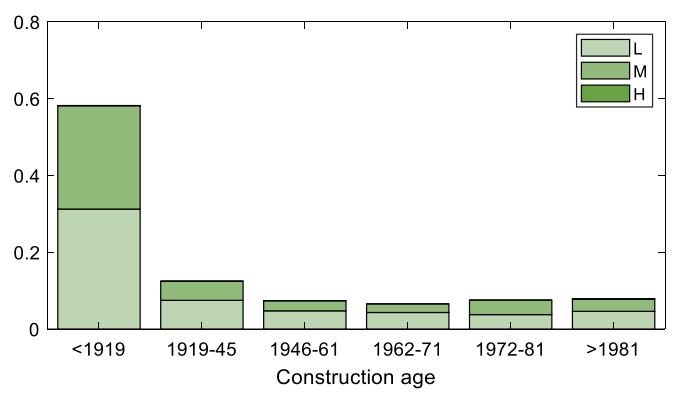

(a)

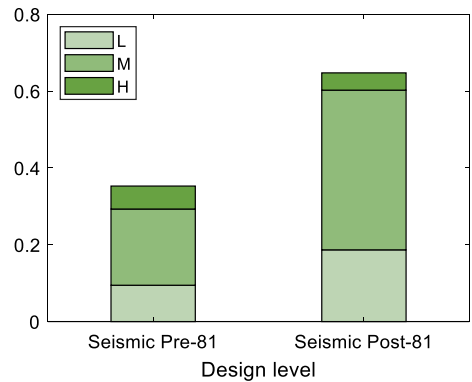

(b)

Fig. 3 Class distribution for $\mathrm{M} \mathbf{a}$ and $\mathrm{RC} \mathbf{b}$ buildings from the post-earthquake dataset 


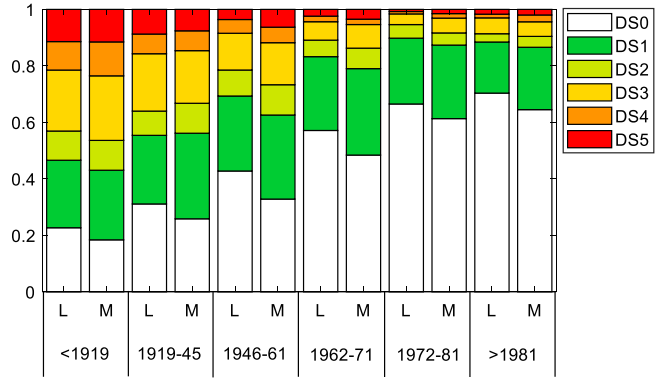

(a)

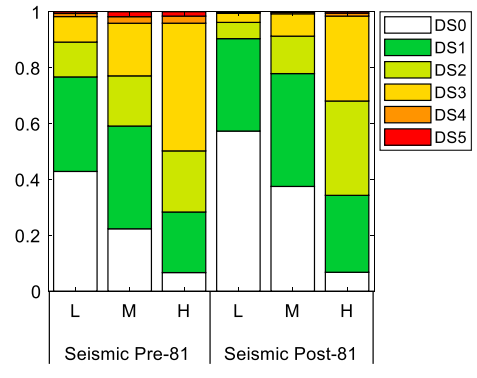

(b)

Fig. 4 Damage distribution for $\mathrm{M} \mathbf{a}$ and $\mathrm{RC} \mathbf{b}$ buildings from the post-earthquake dataset

DS0 to the cases of "no damage", DS1 to the cases of "slight damage", DS2 to the cases of "moderate damage" and DS3 to the cases of "severe damage", regardless of the extent $e$ of the corresponding observed damage.

\subsection{Comparison of fragility curves with post-earthquake damage data}

Figures 5 and 6 compare the fragility models proposed for residential masonry buildings and the observed damage data (black markers), respectively for the various building typologies, i.e., for two classes of building height and six classes of construction age. The size of the black markers refers to the number of buildings in the PGA bin. Similarly, Figs. 7 and 8 present the fragility models proposed for residential RC buildings, three height classes and two vulnerability classes, C2 and D. Regarding RC buildings, a second version of the model by Rosti et al. (2020b) was also introduced and compared. This version better represents the specific scenario of L'Aquila (as well as that of Amatrice), as will be discussed below.

It is worth mentioning that all of the six fragility models were derived for application on a national scale and therefore, for these comparisons, the empirical data of L'Aquila 2009 should not be understood as the correct value (i.e., the deviation of the predicted damage from the observed one should not be interpreted as an error), but rather that it represents a reasonable reference in order to evaluate the trends of the various fragility models.

A first observation, common to all these comparisons, concerns the significant deviation of the fragility curves from the empirical data at the lowest PGA values $(<0.1 \mathrm{~g})$. This fact, as already mentioned, is substantially due to the underestimation of undamaged buildings (DS0) that were not inspected at the low levels of PGA. This obviously leads to overestimating the frequency of occurrence of the other DSs at the same seismic intensities. A different method of processing the empirical data takes into account the negative evidence of damage for buildings located in municipalities with low levels of PGA (through expert judgment and information obtained from the ISTAT census). This is carried out by Rosti et al. $(2020 \mathrm{a}-\mathrm{M})$ and $(2020 \mathrm{~b}-\mathrm{RC})$ for the purpose of calibrating the corresponding fragility models. In these studies, it is possible to observe a trend of the empirical data, after the aforementioned correction, more similar to the logonormal one, which is typical of fragility curves (for further details, refer to Rosti et al. 2020a, b).

Figures 5 and 6 show that the empirical fragility model of Rosti et al. (2020a) accurately predicts (on average) the observed damage distribution for all masonry building typologies. 

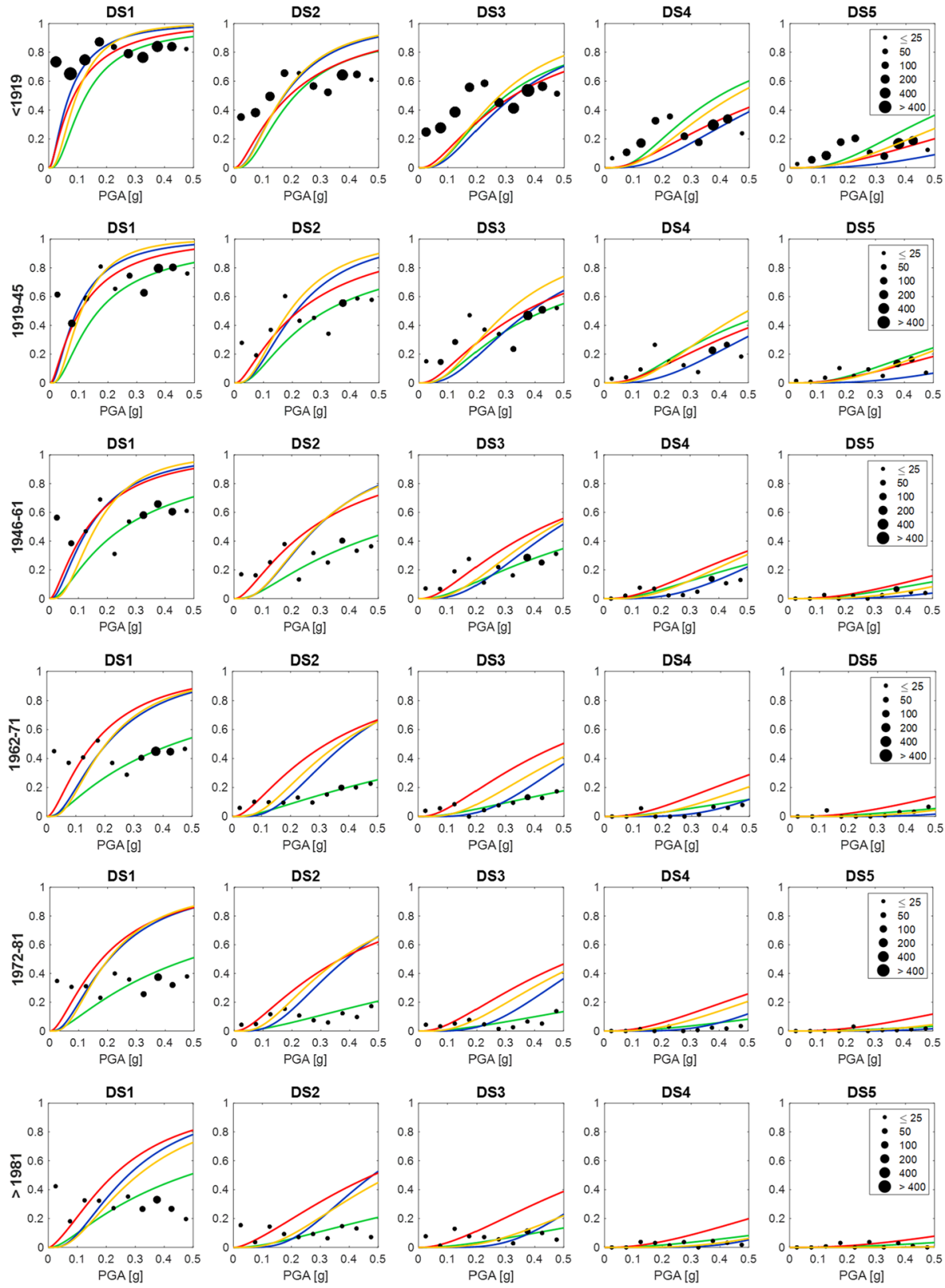

- Donà et al. (2020) — Lagomarsino et al. (2020) — Rosti et al. (2020a) — Zuccaro et al. (2020)

Fig. 5 Comparison of fragility curves for M buildings with 1-2 storeys

Conversely, all other masonry building fragility models follow the empirical data fairly well for low-medium PGA values, but are conservative for higher PGA values, at least up to DS2 (or DS3, excluding the oldest buildings). This means that in the epicentral area 

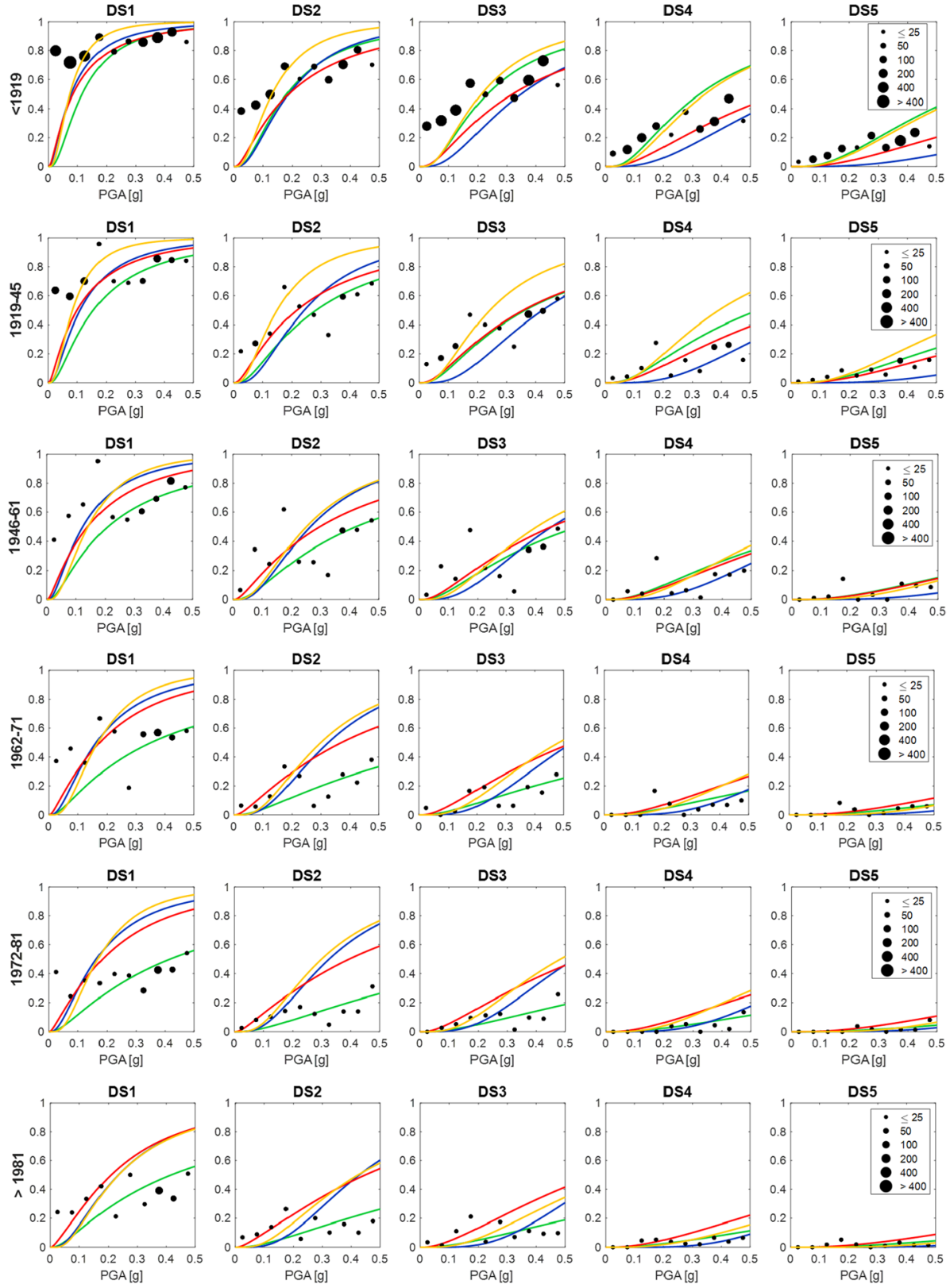

Donà et al. (2020) —— Lagomarsino et al. (2020) —— Rosti et al. (2020a) —Z Zuccaro et al. (2020)

Fig. 6 Comparison of fragility curves for M buildings with 3-5 storeys

(high and medium seismic intensities), all models except the one of Rosti et al. (2020a), are conservative in estimating the number of buildings reaching or exceeding low damage levels. 

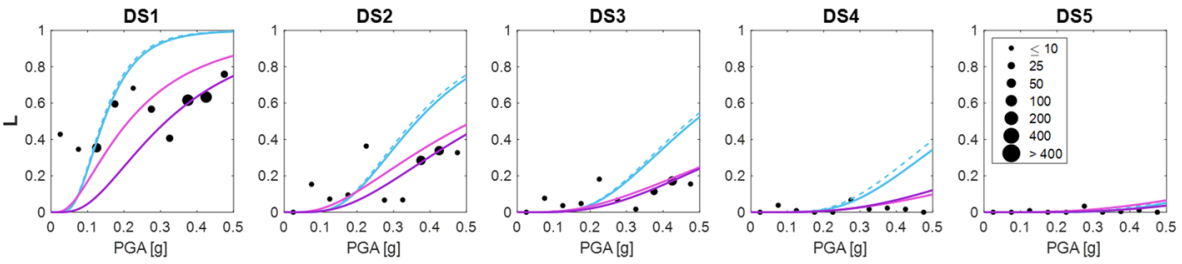

— Borzi et al. (2020b) - 1 storey - - - Borzi et al. (2020b) - 2 storeys — Rosti et al. (2020b) —— Rosti et al. (2020b) - SD
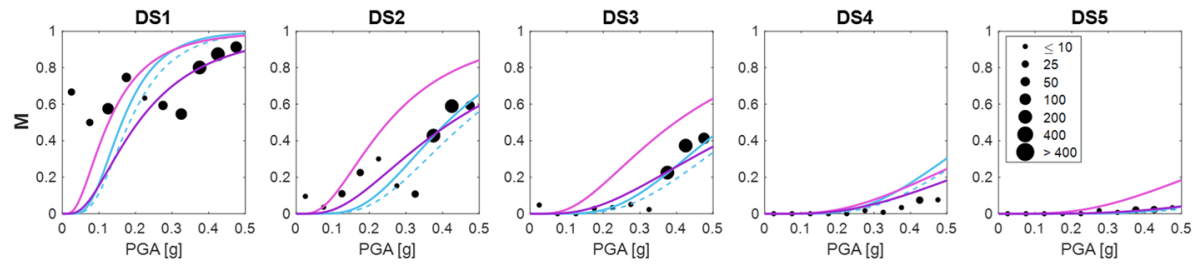

—-Borzi et al. (2020b) - 3 storeys - - Borzi et al. (2020b) - 4 storeys —-Rosti et al. (2020b) —— Rosti et al. (2020b) - SD
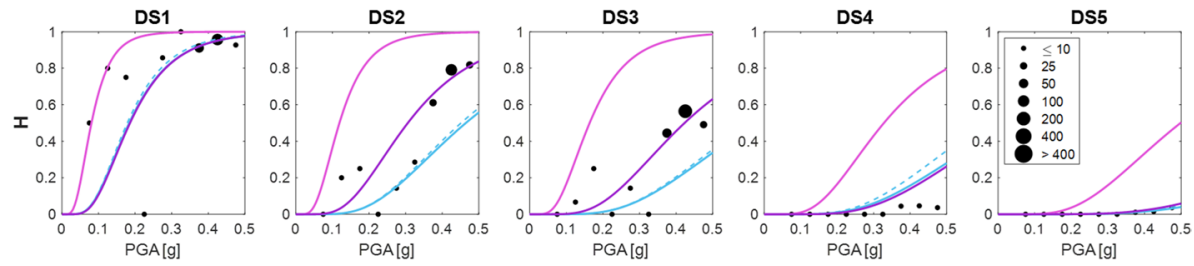

— Borzi et al. (2020b) - 5 storeys - - - Borzi et al. (2020b) - 8 storeys —- Rosti et al. (2020b) —— Rosti et al. (2020b) - SD

Fig. 7 Comparison of fragility curves for RC buildings of vulnerability class $\mathrm{C} 2$ ( $\mathrm{L} \leq 2 ; \mathrm{M}=3-4 ; \mathrm{H} \geq 5$ storeys)

In particular, the model of Donà et al. (2020) is the most conservative (at least up to DS3) for the oldest and, therefore, most vulnerable buildings (i.e., Pre-1919 and 1919-1945, especially with 3-5 storeys). However, for buildings constructed after 1945, the fragility models of Donà et al. (2020), Lagomarsino et al. (2021) and Zuccaro et al. (2020) provide fairly similar damage distributions. Specifically, for post-1945 buildings with 1-2 storeys, the model of Donà et al. (2020) provides intermediate fragility estimates compared to the other two models, and the model of Zuccaro et al. (2020) is generally the most vulnerable. Conversely, considering the 3-5 storey buildings of the same construction periods, the three models show different approaches. The model of Zuccaro et al. (2020) is quite insensitive to the increase in building height, whereas the other two models provide a slight increase in fragility; this leads the fragility curves of Zuccaro et al (2020) being intersected by those of the other two models for the low-medium DSs. However, they do remain the most conservative (albeit slightly) for the major DSs. Consequently, for the highest DSs (DS4 and DS5), the model of Lagomarsino et al. (2021) is the least vulnerable, and this is more evident in older building typologies.

With regard to the standard deviation $(\beta)$ of these fragility curves, the various models offer different solutions because of their different hypotheses of derivation, and this is more evident for the more recent construction ages. In particular, the model of Rosti et al. (2020a) provides the highest values of $\beta$ (to offer the best fit with the empirical data), whereas the model of Donà et al. (2020) provides the lowest (being derived on a mechanical basis); then, the model of Lagomarsino et al. (2021) is characterised by a deviation 

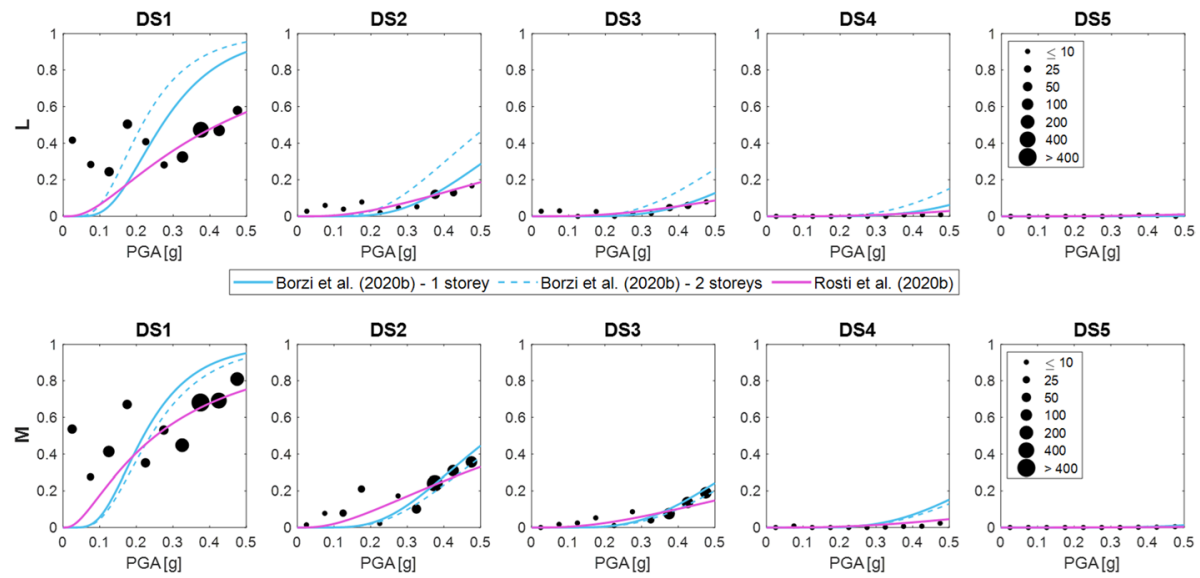

Borzi et al. (2020b) - 1 storey

Borzi et al. (2020b) - 2 storeys — Rosti et al. (2020b)
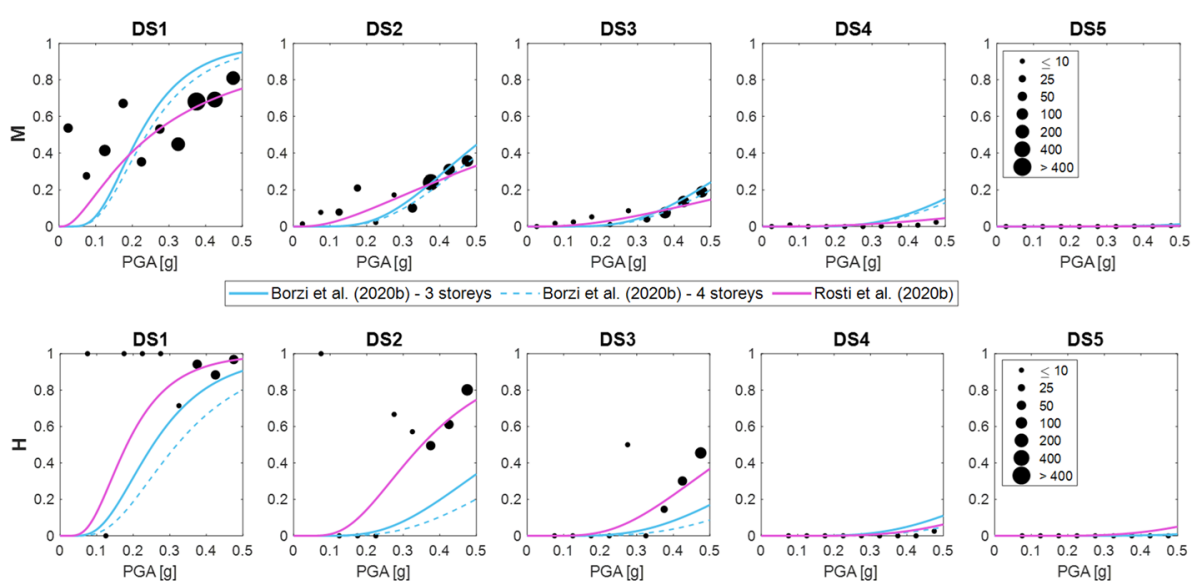

Borzi et al. (2020b) - 3 storeys
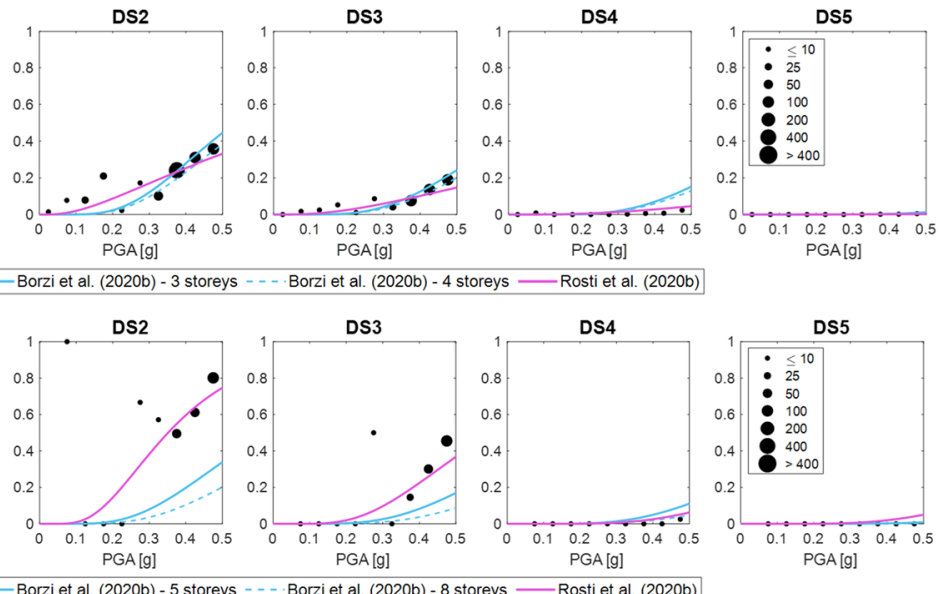

Fig. 8 Comparison of fragility curves for RC buildings of vulnerability class $\mathrm{D}(\mathrm{L} \leq 2 ; \mathrm{M}=3-4 ; \mathrm{H} \geq 5$ storeys)

not much higher that of Donà et al. (2020), as they both refer-through different heuristic procedures - to the macroseismic approach of Lagomarsino and Giovinazzi (2006). Lastly, the model of Zuccaro et al. (2020), which derives from a more general vulnerability model calibrated on a more refined damage database (PLINIVS database, Zuccaro 2004), shows values of $\beta$ larger than the two previous models, but still lower than those of Rosti et al. (2020a).

It is worth noting that two out of the four fragility models do not distinguish fragility for the periods 1962-1971 and 1972-1981 (i.e., those of Donà et al. 2020 and Lagomarsino et al. 2021, see Table 1), and therefore the corresponding fragility curves are to be understood as representative of the overall vulnerability of the two construction periods. Also, for the sake of brevity, we omitted the comparison of fragility curves for masonry buildings with more than five storeys, as they are much less significant due to the limited number of buildings of this typology. In addition, these comparisons offer no further considerations.

Regarding the fragility models for RC buildings, Figs. 7 and 8 show that the empirical model of Rosti et al. (2020b) interpolates the observed damage very well for vulnerability class D (i.e., post-81 seismic design), being calibrated on the same damage information. Instead, as regards class C2 (which includes buildings with both gravity loads and pre81 seismic design), this model turns out to be conservative, globally overestimating the empirical data. The reason for this is that the large majority of the RC residential buildings inspected in L'Aquila had some level of seismic design (even those built before 1981), whereas the model takes into account, to be applied at a national scale, both the presence 
and absence of seismic design. Therefore, for comparison purposes only, a new model was introduced in Fig. 7, i.e. Rosti et al. (2020b)-SD, which differs from the previous model as it defines the fragility of class $\mathrm{C} 2$ as that of buildings with pre-81 seismic design only for consistency with the empirical data of L'Aquila. As can be seen, the fragility predicted by the latter model accurately reproduces the observed damage distribution, being calibrated on it (for more details, see Rosti et al. 2020b).

The model of Borzi et al. (2020b), being defined separately for all storey numbers from 1 to 8 (see Table 2), is shown for 1 and 2-storey buildings in class L, 3 and 4-storey buildings in class $\mathrm{M}$ and a 5 and 8-storey buildings in class $\mathrm{H}$ (>4 storeys); the variation of these curves within the same height class is significant only for the vulnerability class D.

Compared to the observed damage, and therefore to the model of Rosti et al. (2020b)SD, the model of Borzi et al. (2020b) is slightly conservative for low-rise buildings (class $\mathrm{L}$ ), slightly non-conservative for tall ones (class $\mathrm{H}$ ), and in line for those of intermediate height (class M). Indeed, although this model is of mechanical derivation, it was calibrated on post-earthquake damage data, including that of L'Aquila 2009, using the Da.D.O. database.

With regard to the standard deviation of these fragility curves, the empirical model of Rosti et al. (2020b) shows higher $\beta$ values than the mechanical model of Borzi et al. (2020b), which was expected considering the different origins of the two models. When it comes to the model of Borzi et al. (2020b), this further contributes to obtaining conservative damage estimates for high PGA values in the case of low-medium rise buildings (in particular of class D), and this is more evident at the lowest DSs.

The accuracy of the prediction of the various fragility models with respect to the observed damage data was quantified, for all building classes and damage levels, in terms of root mean square error (RWMSE), weighted by the number of buildings associated with each empirical data point, according to the following equation:

$$
R W M S E=\sqrt{\sum_{i=1}^{n} w_{i}\left(y_{i}-\hat{y}_{i}\right)^{2}}
$$

where $n$ is the number of empirical data points, $w_{i}$ is the weight associated with the $i$ th data point, and $y_{i}$ and $\hat{y}_{i}$ are the predicted and observed probability of reaching or exceeding the considered damage level. The values of the RWMSE parameter are shown in Figs. 9 and 10 , respectively for masonry and RC buildings, for some significant building classes and all DSs.

Both these figures highlight the significant deviation from the observed damage at the lowest DSs. This is due, as previously mentioned, to the incompleteness of the empirical data, and the underestimation of the negative evidence of damage (DS0) at the lowest PGAs, which consequently affects the damage distribution for low DSs. As the level of damage increases, and therefore also the reliability of the empirical data (given that more severe damage occurs for larger PGAs, for which the survey was instead complete), a rapid reduction in the RWMSE values is observed for all models, confirming the reasonableness of their damage predictions. In particular, Fig. 9 shows that these values do not vary significantly with the age of construction nor the height class of masonry buildings, except for the model by Rosti et al. (2020a), which provides increasingly lower values as the year of construction increases. From Fig. 10 it can be seen that the lowest RWMSE values for RC buildings (which are even slightly lower than those obtained for masonry buildings), are provided by the model of Rosti et al. (2020b) for vulnerability class D, and by the model of 

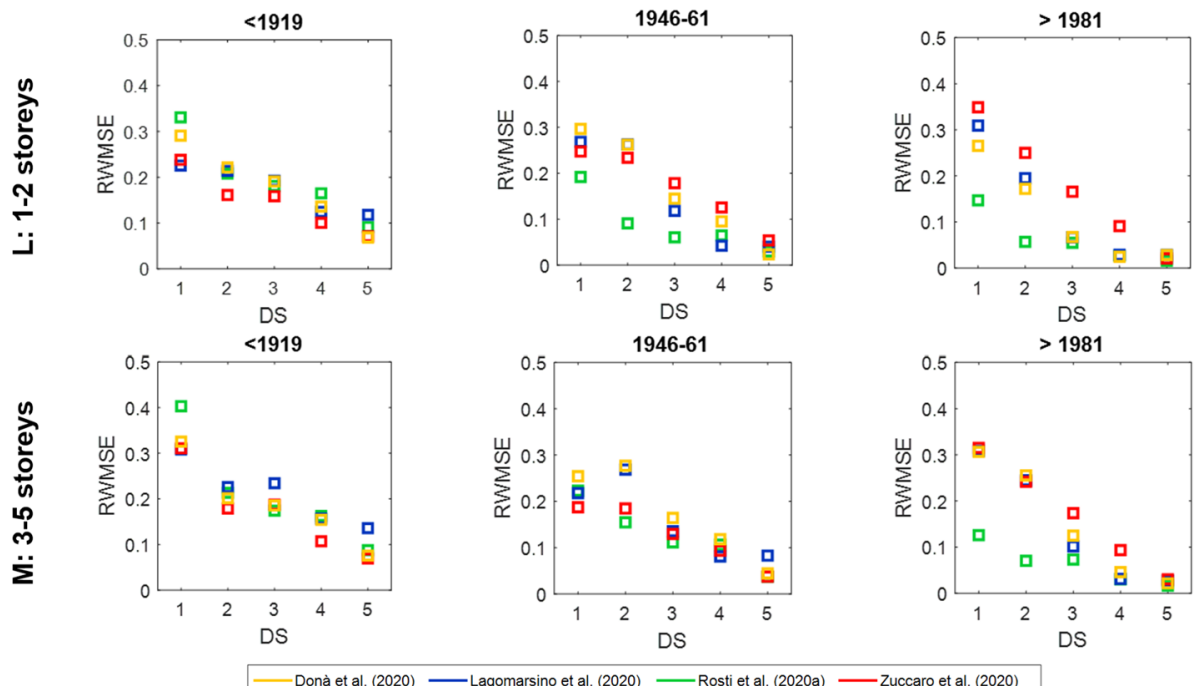

Fig. 9 RWMSE values for the fragility models of M buildings
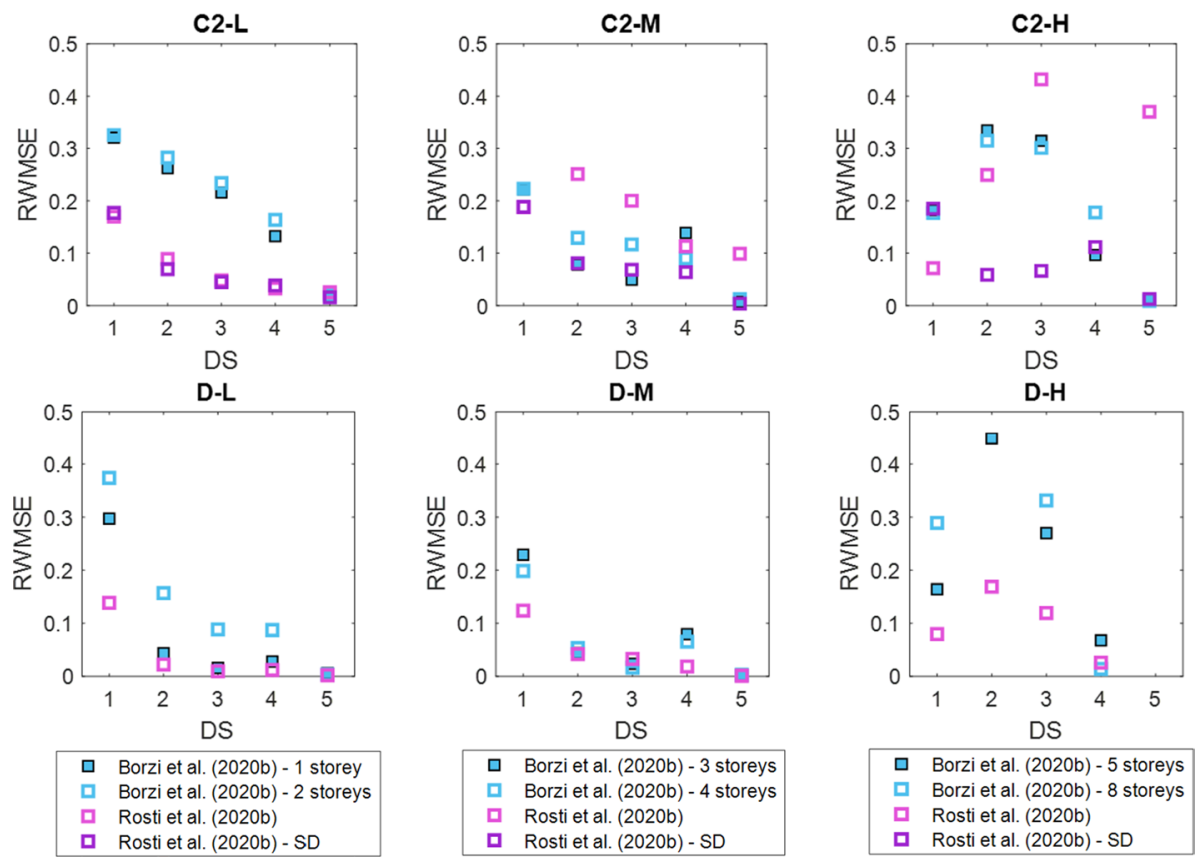

Fig. 10 RWMSE values for the fragility models of RC buildings

Rosti et al. (2020b)-SD for class C2, for the reasons discussed above. Conversely, the model of Borzi et al. (2020b) shows slightly higher values than the previous ones. Lastly, for the tallest RC buildings, the highest values and the most dispersed trends of the RWMSE are 
observed. This result is due to an observed damage database which is more limited in the case of RC buildings, compared to $\mathrm{M}$ buildings, and less uniform for the various building classes with respect to the DS and PGA parameters. Indeed, as can be seen from Figs. 7 and 8, the empirical data relating to building classes $\mathrm{C} 2-\mathrm{H}$ and $\mathrm{D}-\mathrm{H}$ is less populated and concentrated at the highest values of the PGA (i.e., buildings damaged in the epicentral area), where the differences compared to the models of Borzi et al. (2020b) and Rosti et al. (2020b-only for class C2, including RC buildings with gravity load design) are greater.

\subsection{Comparison of predicted and observed damage distributions and scenarios}

Figures 11 and 12 show the observed and predicted damage distributions (from DS0 to DS5), respectively for $\mathrm{M}$ and $\mathrm{RC}$ buildings, considering all the buildings of the completelysurveyed municipalities, grouped by increasing levels of PGA (with steps of $0.1 \mathrm{~g}$ ). The observed damage distribution was obtained from the georeferenced information of detected damage (shown in summary by building typology in Fig. 4) and from the PGA values of the L'Aquila ShakeMap (Fig. 2b). The empirical data of the total number of buildings by PGA level and typology was used as a reference to determine the damage distributions predicted by the various models, scaling the occurrence frequencies (in \%) of the various DSs obtained from the macro-typological fragility curves for the chosen PGA. Hence, Figs. 11 and 12 are derived by combining the damage distributions of all typologies for incremental levels of PGA, separately for M and RC buildings.

Both figures clearly show that as the PGA increases, the occurrence of minor DSs decreases in favour of the major DSs, as expected. In the case of M buildings, in which about $60 \%$ of the buildings belong to the Pre-19 typology (see Fig. 3a), the damage distribution is fairly regular at high PGA levels, with intermediate damage states (DS2 and DS3) being the most frequent. On the other hand, in the case of RC buildings, in which more
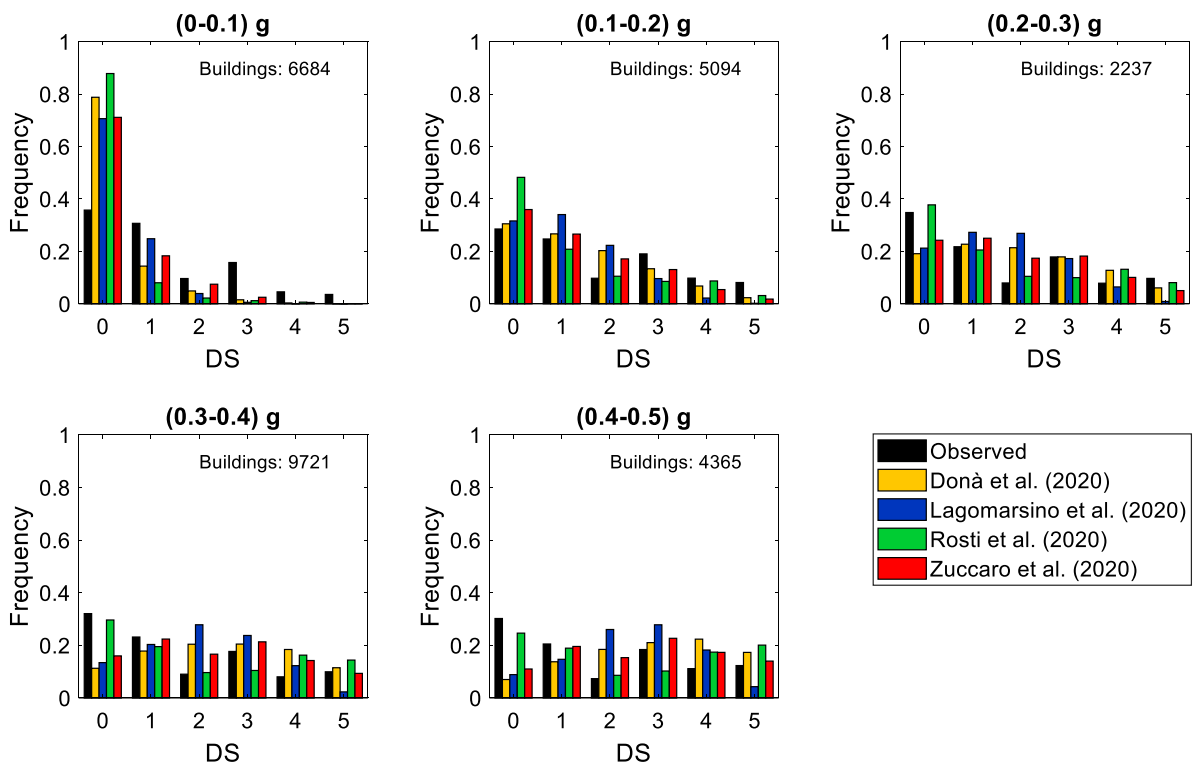

Fig. 11 Observed and predicted damage distributions at various levels of PGA for M buildings 

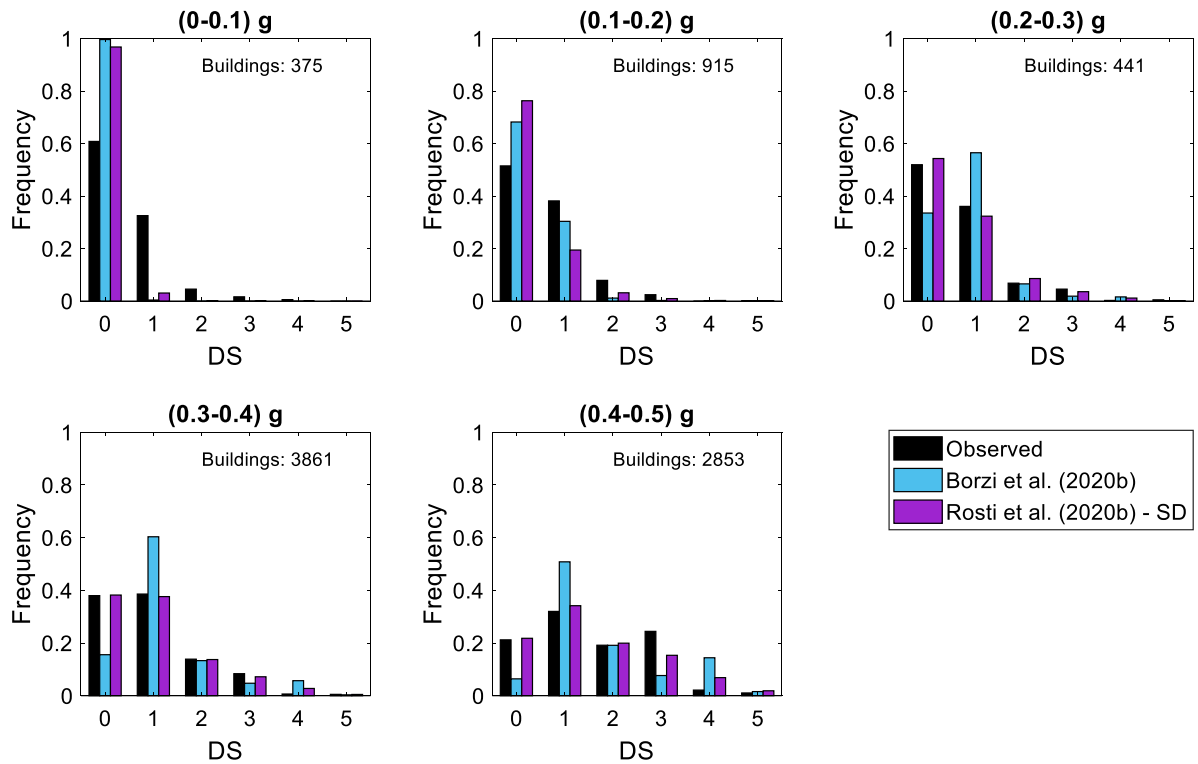

Fig. 12 Observed and predicted damage distributions at various levels of PGA for RC buildings

than $60 \%$ of the buildings are classified as Seismic Post-81 (see Fig. 3b), and the damage distribution is overall less severe, DS1 remains the most frequent damage state even at the highest PGAs.

Furthermore, Figs. 11 and 12 once again highlight the underestimation of the empirical DS0 at the lower PGAs (discussed above), which affects the corresponding damage distribution; as the level of PGA increases, and so the reliability of the empirical data, the comparison between observed and predicted damage distribution improves significantly, although some differences remain. In particular, there is a singular trend in the distribution of observed damage in the case of M buildings (but also for RC buildings at the highest PGAs), i.e. the occurrence of DS2 is always lower than that of DS3. This might be justified by the "conservative sensitivity" of some inspectors to identify a damage slightly higher than DS1 as DS3, considering that DS3 represents a threshold to justify the judgment of unusability and the expeditious nature of the damage survey. Thus, this excludes DS2 from the damage metric.

Regarding the comparison between the predicted damage distributions for $\mathrm{M}$ buildings, the model of Rosti et al. (2020a) provides the major occurrences of DS0 and, consequently, the minor occurrences of the intermediate DSs (DS2 and DS3), and the model of Lagomarsino et al. (2021) shows the minor occurrences of the most severe DSs (DS4 and DS5). This trend can be seen over the whole range of PGAs analysed, but is more evident, in relative terms, at the larger PGAs. Concerning RC buildings, the model of Borzi et al. (2020b) provides higher occurrences of DS1, underestimating DS0, compared to the model of Rosti et al. (2020b)-SD. All this is justified by the trends of the various fragility curves, previously discussed.

The comparison among the various fragility models was also carried out in terms of observed and predicted damage scenarios, through the use of I.R.MA, evaluating the percentages of buildings that reach or exceed certain DSs. In particular, Fig. 13 shows the observed damage scenarios considering only residential masonry buildings, for the damage 
levels DS1, DS3 and DS4 (assumed as the most representative of the EMS98 damage scale). The corresponding damage scenarios predicted by the various fragility models are shown in Fig. 14. Figure 15 shows the observed damage scenarios for the residential RC buildings, still for the damage levels DS1, DS3 and DS4; the corresponding predicted damage scenarios are shown in Fig. 16.

As regards the damage scenarios for masonry buildings, Figs. 13 and 14 show that all relevant fragility models reasonably predict the damage observed after this specific seismic event. In general, the empirical model of Rosti et al. (2020a) provides the damage estimates that most closely resemble the measured ones, being calibrated on the same damage information. The other models, on the other hand, slightly overestimate the DS1, predicting a larger number of damaged buildings in the municipalities of the epicentre and a larger extension of the area affected by this damage level (albeit with low percentages of buildings involved). This result is in agreement with the previous observations made on the corresponding fragility curves; indeed, for medium and high PGA values, these curves provide conservative damage distributions with respect to the empirical data, especially for the lowest DSs. Moreover, the curves of the models of Zuccaro et al. (2020) and Lagomarsino et al. (2021) have a higher standard deviation than those of the model by Donà et al. (2020), hence the former models provide higher damage estimates for low PGA values and larger areas affected by damage. Regarding the DS3 and DS4 damage scenarios, all models provide similar predictions, with those of Donà et al. (2020) and Zuccaro et al. (2020) following the observed damage better, and those of Lagomarsino et al. (2021) being slightly non-conservative, all in accordance with the lower vulnerability of its fragility curves at higher DSs.

With regards to the damage scenarios of RC buildings, shown in Figs. 15 and 16, both fragility models of Borzi et al. (2020b) and Rosti et al. (2020b)-SD provide reasonable predictions, which are in good agreement with the observed damage. In particular, there is a slight overestimation of DS1, in the epicentral zone, by the model of Borzi et al. (2020b), since the corresponding fragility curves, as previously observed, show a lower dispersion with consequent overestimates of damage for the higher PGA values (in particular for lowmid rise buildings). Some municipalities in all maps of Fig. 16 are not colored (i.e., they are white), as there are no RC buildings in those municipalities.

For a more general evaluation of the effectiveness of the fragility models, Fig. 17 compares the observed and predicted damage distribution for all models, based on the entire post-earthquake reference database and corresponding simulations in I.R.MA. This representation is particularly useful, as it immediately shows the overall underestimation or overestimation of the model for each DS, with respect to the observed damage

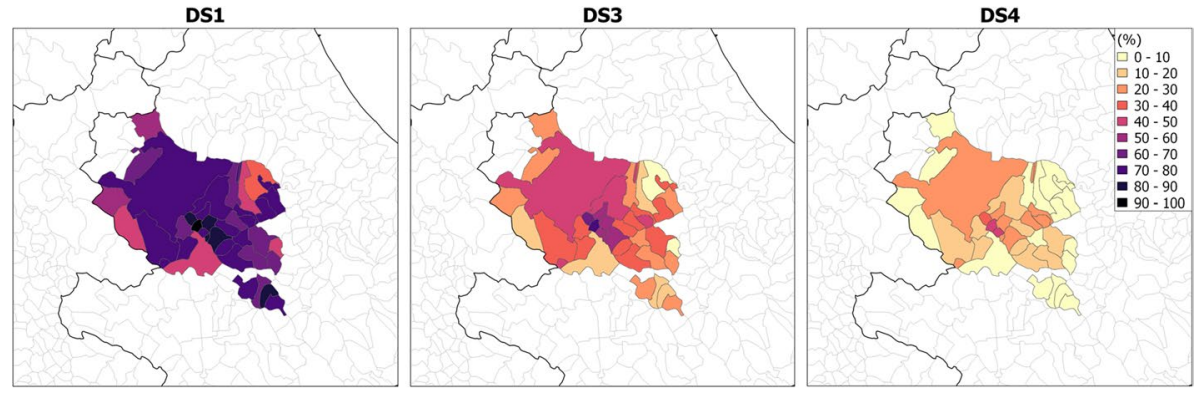

Fig. 13 Observed damage scenarios - 2009 L'Aquila earthquake: \% M buildings that reach/exceed the DSs 

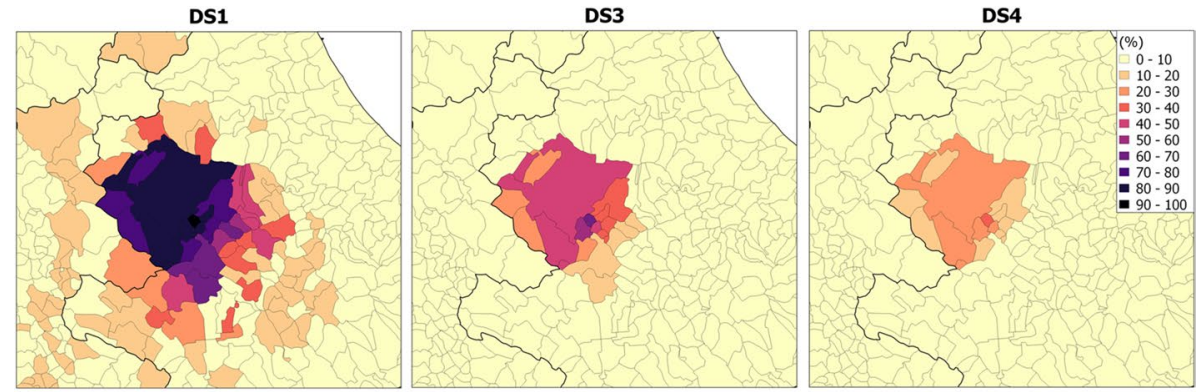

Donà et al. (2020)
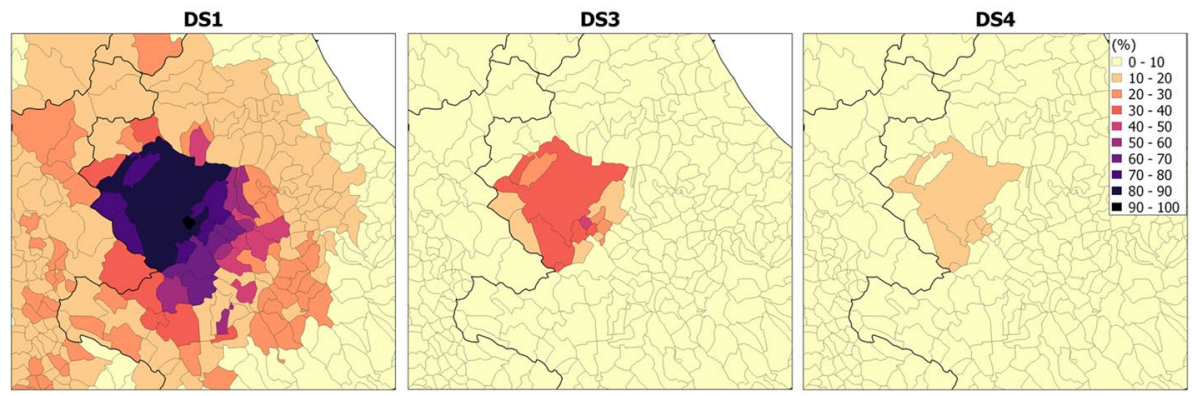

Lagomarsino et al. (2020)
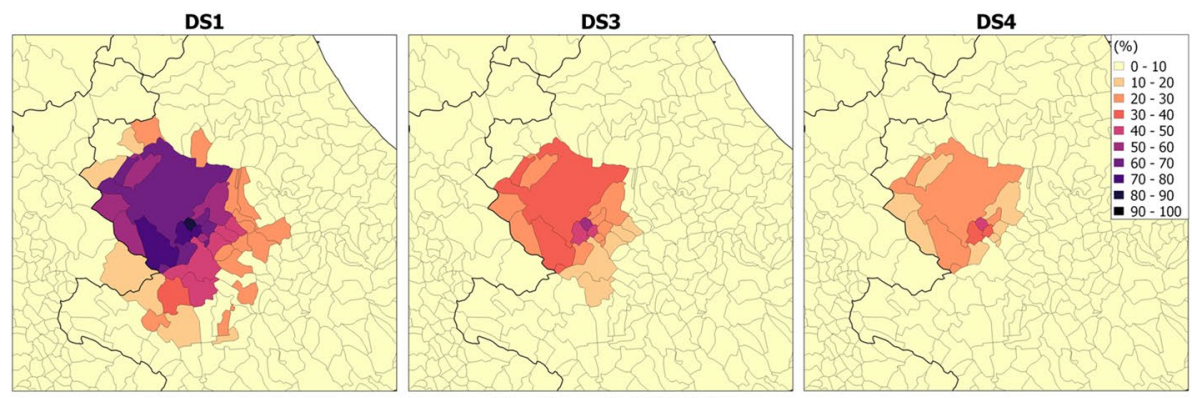

\section{Rosti et al. (2020a)}
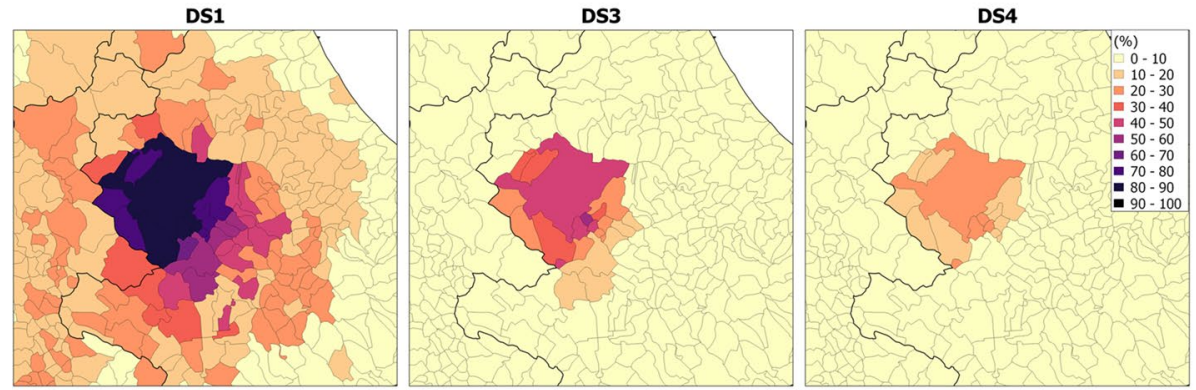

Zuccaro et al. (2020)

Fig. 14 Predicted damage scenarios-2009 L'Aquila earthquake: \% M buildings that reach/exceed the DSs 


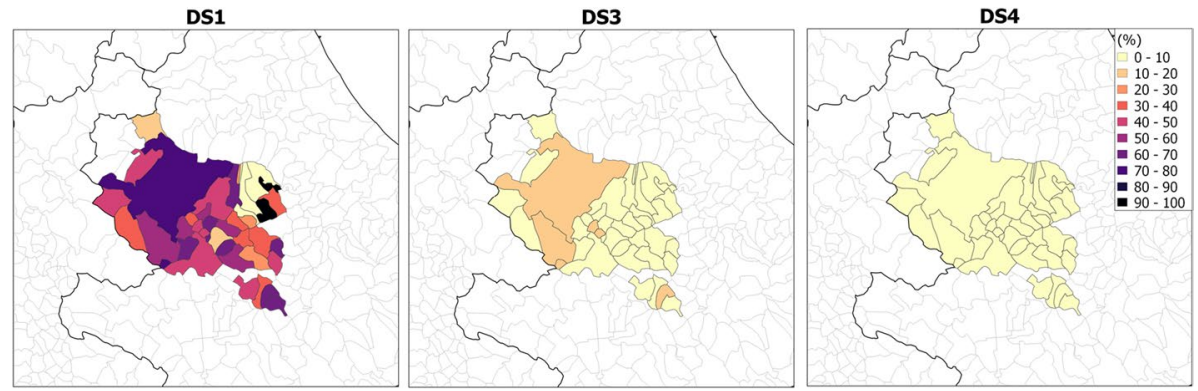

Fig. 15 Observed damage scenarios_-2009 L'Aquila earthquake: \% RC buildings that reach/exceed the DSs
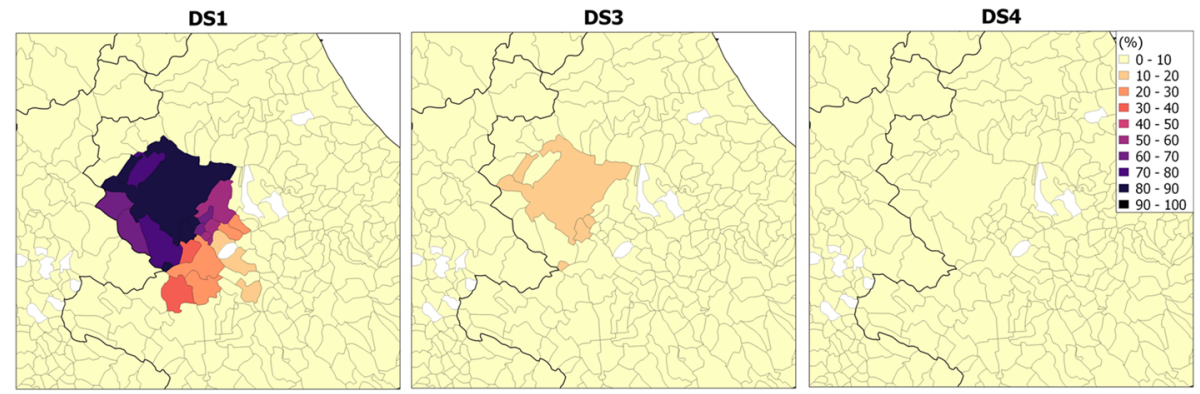

Borzi et al. (2020)
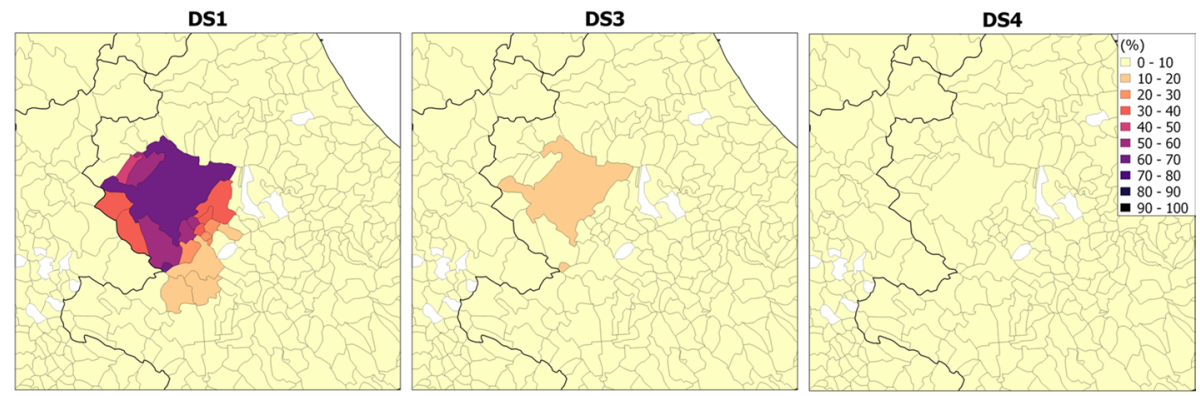

Rosti et al. (2020b) - SD

Fig. 16 Predicted damage scenarios_-2009 L'Aquila earthquake: \% RC buildings that reach/exceed the DSs

(with the marker indicating the DS respectively below or above the bisector). The results show that, although the damage distributions predicted by the various models are different, they all follow the observed data reasonably well, demonstrating the adequacy of all the models for the purposes of this study. In particular, for masonry buildings, quite similar results are observed for the models of Donà et al. (2020), Zuccaro et al. (2020) and Lagomarsino et al. (2021), despite their different derivation hypotheses. The model of Rosti et al. (2020a), on the contrary, behaves in a slightly different way, by giving the best predictions for the higher DSs, being calibrated on the empirical data of this earthquake. For the same reason, the best fit for the observed damage distribution of RC buildings is given by the model of Rosti et al. (2020b)-SD, whereas the model 

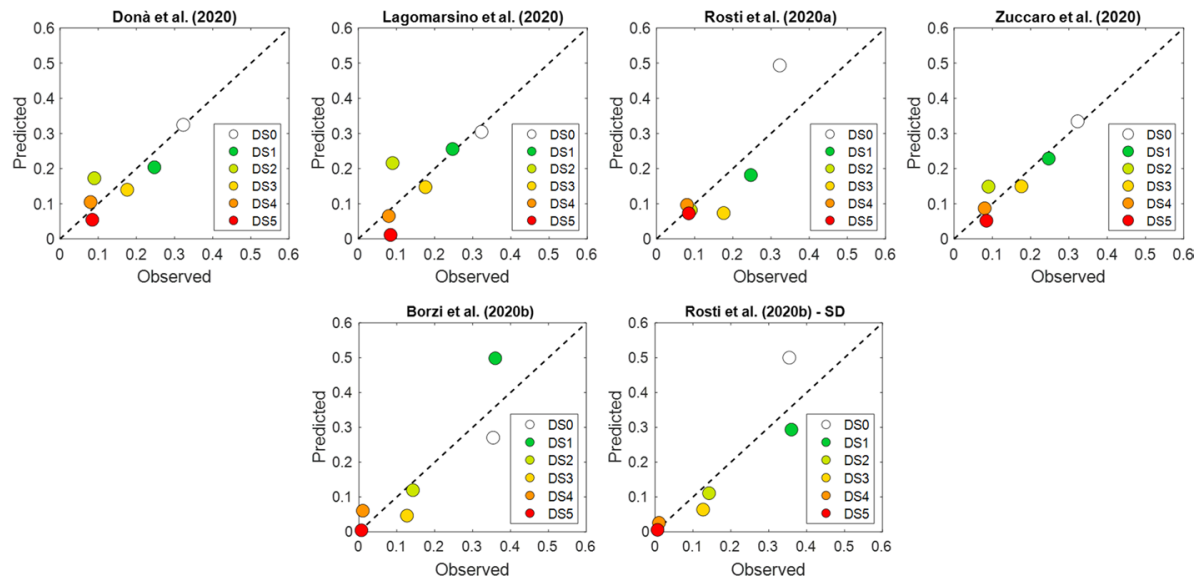

Fig. 17 Comparison of observed and predicted damage distribution for M (top) and RC (bottom) buildings

of Borzi et al. (2020b) provides more conservative predictions for DS1. It is also worth noting that the distribution of occurrence of DSs (from DS1 to DS5) is more uniform for masonry buildings than RC buildings. Actually, the latter have a relatively higher occurrence probability of absence of damage (DS0) and low damage (DS1), thus DSs from DS2 to DS5 are flattened to low values of occurrence. This is mainly due to the macro-typologies of $\mathrm{M}$ and $\mathrm{RC}$ buildings involved in this seismic event, and is in agreement with the observations made on the distribution of damage by PGA levels (Figs. 11 and 12).

Lastly, Fig. 18 focuses on the predictive ability of fragility models for low values of seismic intensity. It compares the observed and simulated damage distributions in municipalities far from the epicentre and ones only slightly affected by the earthquake, which were, as a result, not inspected or inspected with a survey completeness ratio less than 0.1 . For this comparison, the unispected buildings in these municipalities were reasonably considered as undamaged (DS0). For display purposes, the damage frequency (y-axis) is plotted on a logarithmic scale. As can be seen on the graphs, the comparison with the observed data is quite promising for all models, which therefore prove to be adequately sensitive even to low PGA values (the most significant difference is noted for RC buildings, at the higher DSs).
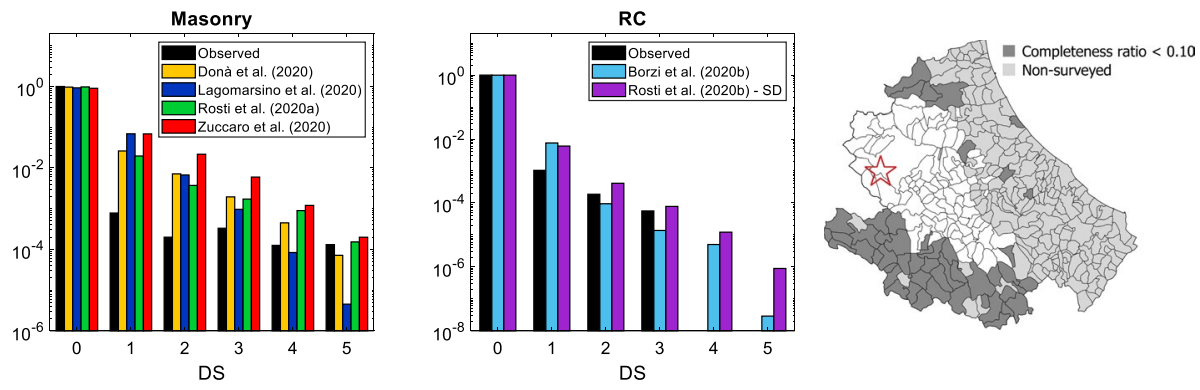

Fig. 18 Observed and predicted damage distributions (y-axis in logarithmic scale), considering the nonsurveyed municipalities (light grey) and those with completeness ratio less than 0.1 (dark grey) 


\subsection{Comparison of consequences on building stock and population}

As above explained, by applying appropriate models, it is possible to derive risk estimates from damage predictions in terms of direct economic losses (Table 3), human losses (Table 4) and impact on buildings/dwellings (Table 5). Figures 19 and 20 show these risk estimates, respectively for $\mathrm{M}$ and $\mathrm{RC}$ buildings of the municipality of L'Aquila.

Comparing risk estimates of various fragility models for $\mathrm{M}$ buildings, the following observations can be drawn. The model of Donà et al. (2020) is slightly more conservative than the others in predicting direct economic losses. This is due to the fact that the majority of M buildings in L'Aquila was built before 1919 (about 40\%) and, as observed from the fragility curves comparison, those of the Donà et al. (2020) model are the most vulnerable for this building typology at low and medium DSs. Indeed, the damage states up to DS3 strongly affect the overall economic losses notwithstanding their lower unit cost (see Table 3), due to the higher occurrence (as observed in the damage scenario of Fig. 14).

The model of Rosti et al. (2020a) is slightly more conservative than the others in predicting casualties and injury, despite its fragility curves are generally less conservative than the others. This is again due to the high percentage of pre-19 buildings, for which the model of Rosti et al. (2020a) is more vulnerable at DS4 and DS5, which are assumed as the only damage states associated with human losses in our model (Table 4). Conversely, the model of Lagomarsino et al. (2021), which is generally the least vulnerable at the highest DSs, is the one that provides the lowest figures for human losses, for the above-mentioned reason. Lastly, one of the main differences in the building impact estimates concerns the lower number of collapsed buildings of the model of Lagomarsino et al. (2021), still for

(a)

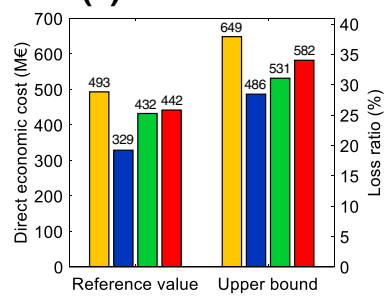

(b)

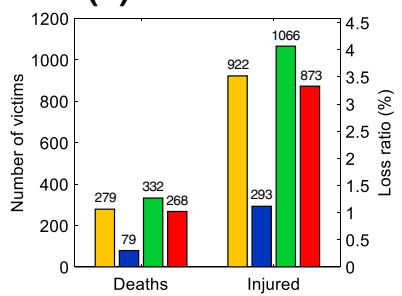

(c)

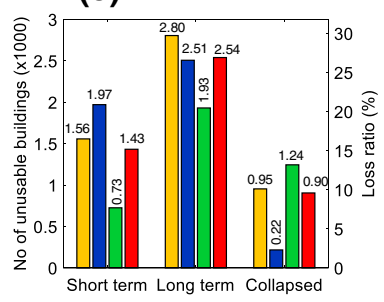

Donà et al. (2020) $\square$ Lagomarsino et al. (2020) $\square$ Rosti et al. (2020a) $\square$ Zuccaro et al. (2020)

Fig. 19 Direct economic losses $\mathbf{a}$, human losses $\mathbf{b}$ and building impact $\mathbf{c}$ for $\mathbf{M}$ buildings in L'Aquila

(a)

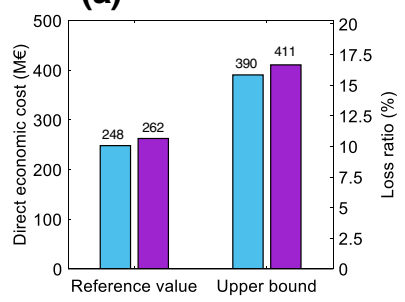

(b)

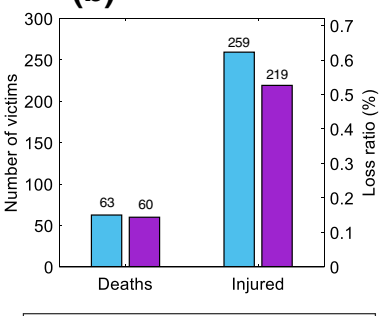

(c)

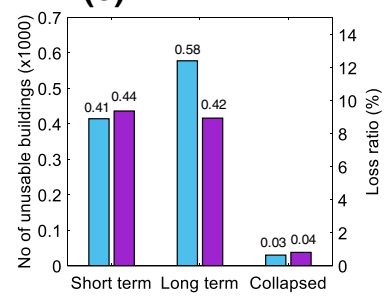

Fig. 20 Direct economic losses a, human losses $\mathbf{b}$ and building impact $\mathbf{c}$ for RC buildings in L'Aquila 
the same reason. Another difference is the lower number of short- and long-term unusable buildings provided by the model of Rosti et al. (2020a), due to the overall lower vulnerability of its fragility curves, at least up to DS3.

With regards to the risk estimates for RC buildings, the models of Borzi et al. (2020b) and Rosti et al. (2020b)-SD provide similar figures.

To compare risk estimates with real figures, there are different data sources to get quantitative information for the municipality of L'Aquila. In particular, Di Ludovico et al. $(2017 \mathrm{a}, \mathrm{b})$ provides information on the total cost of recostruction (including repair and retrofit, without VAT) to be 265 million euro for M buildings, hence lower than the model estimates, and 1145 million euro for RC buildings, thus well above forecasts. However, considering the overall built heritage of the L'Aquila municipality, the average UpperBound estimate of the various models is quite close to the overall actual costs. The reasons for such a difference between predicted and real values are various, but the most significant is the use of a unique simplified damage-to-direct economic loss model for all $\mathrm{M}$ and RC buildings. This could be further refined to take into account the possible influence of various building types on the intervention costs.

Regarding the human losses, the average forecast of the various models (300 deaths) is in line with the real data of 268 deaths for the L'Aquila municipality (Rossetto et al. 2011). However, if we consider in detail the distribution of those casualties between RC buildings (147, see Alexander and Magni 2013) and M buildings (121, by difference from the previous figure), we again find an inverted trend between model predictions and real data, which again could be mainly due to the use of a unique simplified damage-to-human loss model for all building typologies. The overall injured on the whole affected area were about 1600 , most of which presumably in the L'Aquila municipality; therefore, the corresponding forecast are also reasonable on average (1027 injured).

Lastly, the prediction of the seismic impact on buildings is of the same order of magnitude with respect to the information from the Aedes forms reported in Da.D.O., although quite non-conservative. In particular, considering both the $\mathrm{M}$ and $\mathrm{RC}$ buildings-as the forecasts are still based on a unique simplified damage-to-building impact model-the average estimate of the various models for short-term unusability is 1847 buildings, compared to the actual 3400. The average forecast that includes long-term unusability and collapse is 3086 buildings, compared to the actual 5792. Clearly, a much better comparison could have been obtained by calibrating the damage-to-building impact model specifically on the macro-typologies of M and RC buildings of L'Aquila area. However, considering the general objective of this comparative assessment, although based on a specific scenario, we preferred to use an impact model defined on a larger damage database, valid at a national scale, as described in Sect. 2.

\section{The Amatrice seismic event (2016)}

\subsection{The 2016 Central Italy earthquake}

Another comparison of the performance of the fragility models is based on the 2016 Amatrice earthquake (magnitude moment $M_{w}=6.0,299$ deaths and 390 injured), which was the first main event (on August, 24) of a significant seismic sequence (defined as Amatrice-Norcia-Visso sequence) that hit a large area of central Italy between 2016 and 2017, 
Fig. 21 ShakeMap of the first main event of the Central Italy sequence, August 24, 2016

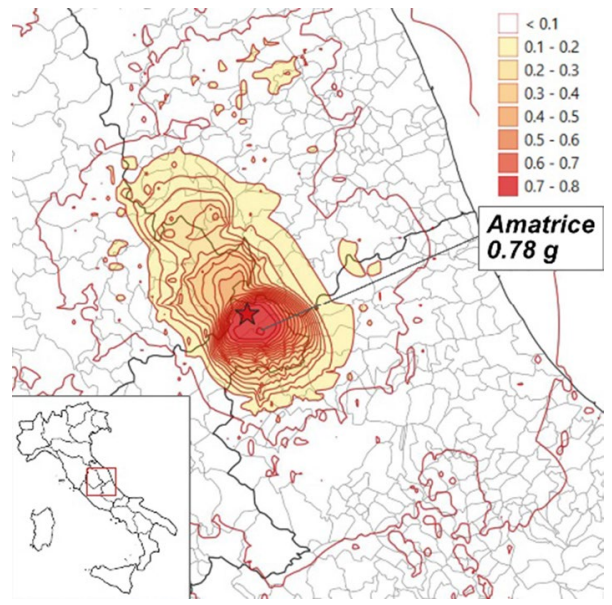

resulting in a total of approximately 41,000 displaced persons. The ShakeMap of the Amatrice earthquake is shown in Fig. 21 (available on the INGV website).

For this earthquake, the damage survey of residential buildings was also extensively carried out for all of the involved municipalities using the AeDES form (Baggio et al. 2007). Unfortunately, this information has not yet been fully processed and uploaded into the Da.D.O. database (Dolce et al. 2019), and therefore cannot be used as a comparison for damage predictions. It is also worth mentioning that significant damage accumulation phenomena were observed in some of the municipalities, due to the effects of the entire seismic sequence.

\subsection{Comparison of predicted damage scenarios}

The comparisons between the damage scenarios of the 2016 Amatrice earthquake, predicted by the various fragility models, are reported in Figs. 22 and 23, respectively for $\mathrm{M}$ and RC buildings. In the case of RC buildings, Rosti et al. (2020b)-SD was chosen, as also in Amatrice there were no RC buildings with gravity load design, similarly to L'Aquila. As can be seen, the damage predictions given by the various fragility models are still reasonably consistent, and the same comparative observations made for the 2009 L'Aquila earthquake can also be applied in this case.

In particular, from the damage scenarios of masonry buildings in Fig. 22, it is still possible to observe a less severe DS1 damage scenario provided by the model of Rosti et al. (2020a), both in terms of percentage of damaged buildings in the epicentral area and geographical extent of the damage. It is also possible to observe a fairly similar prediction of the DS3 scenario by the various models, and a less severe DS4 scenario provided by the model of Lagomarsino et al. (2021). The larger PGA values produced by this earthquake and its larger geographical extension, compared to that of L'Aquila 2009, make the aforementioned differences among models even more evident. This also results in damage estimates being generally more severe.

As regards the damage scenarios of RC buildings in Fig. 23, the model of Borzi et al. (2020b) is still the most conservative in estimating the number of buildings reaching or exceeding DS1 in the municipalities of the epicentre. In addition, it provides slightly more severe DS3 and DS4 damage scenarios than that of Rosti et al. (2020b)-SD, which 

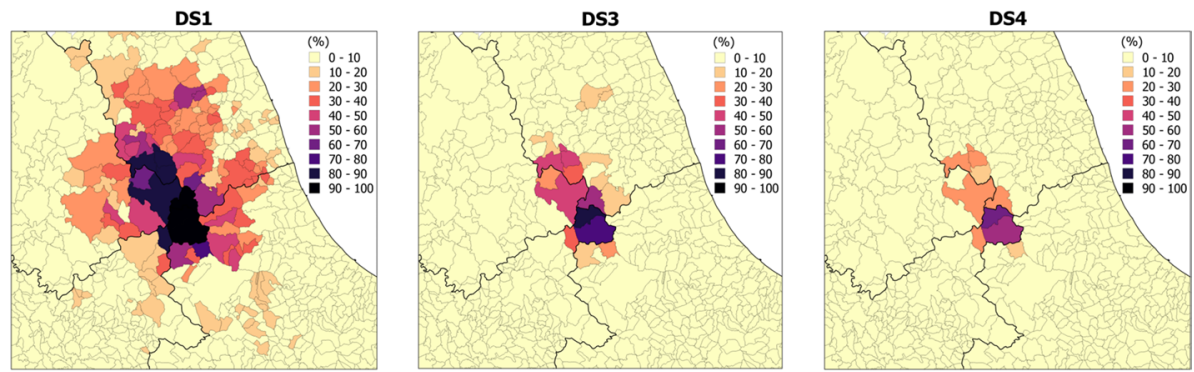

Donà et al. (2020)
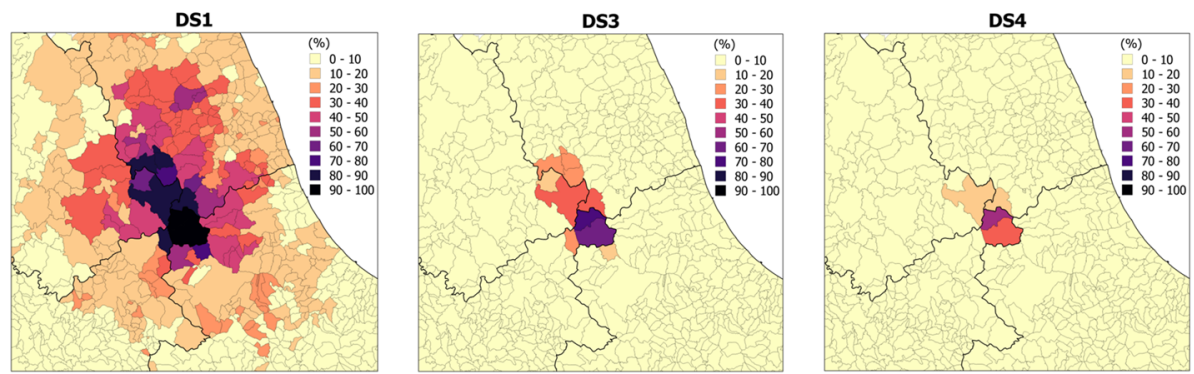

Lagomarsino et al. (2020)
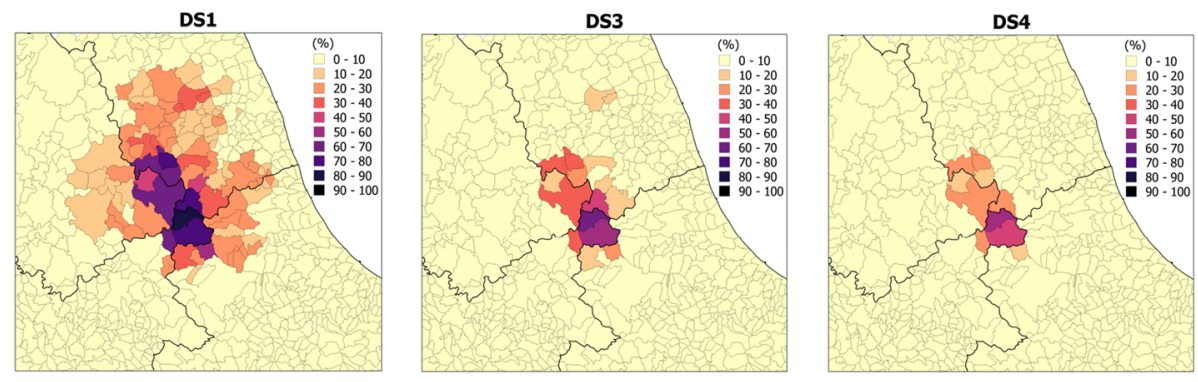

Rosti et al. (2020a)
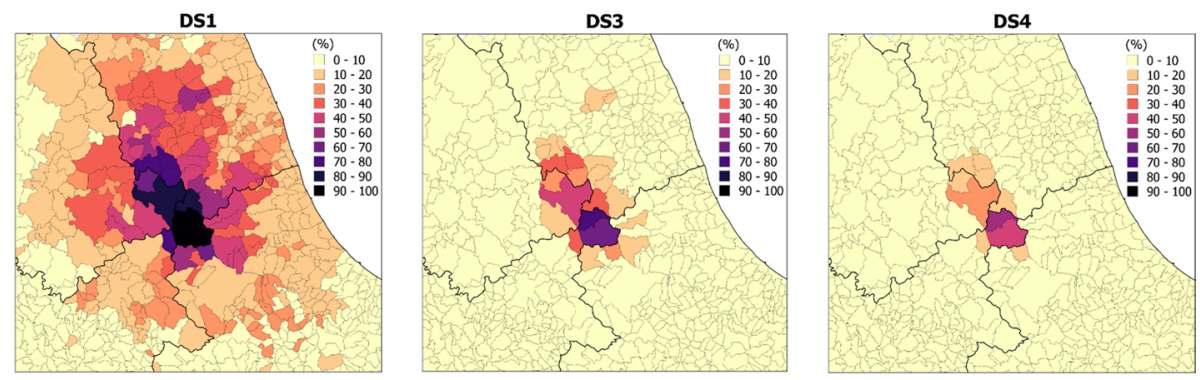

Zuccaro et al. (2020)

Fig. 22 Predicted damage scenarios-2016 Amatrice earthquake: \% M buildings that reach/exceed the DSs 

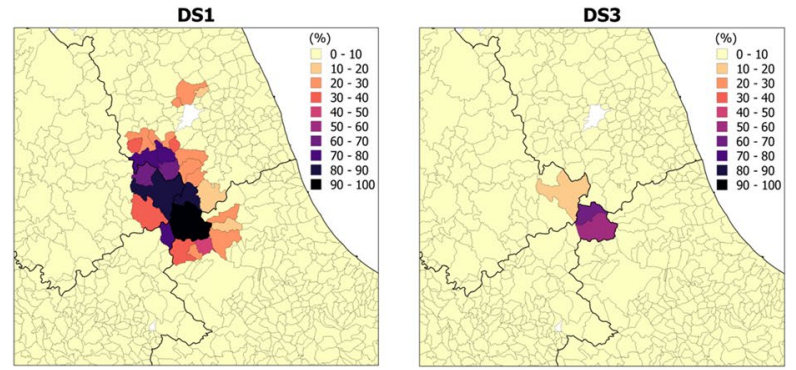

Borzi et al. (2020b)

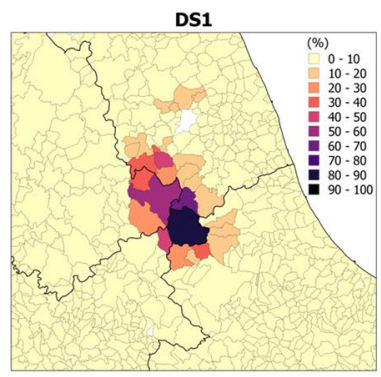

DS3

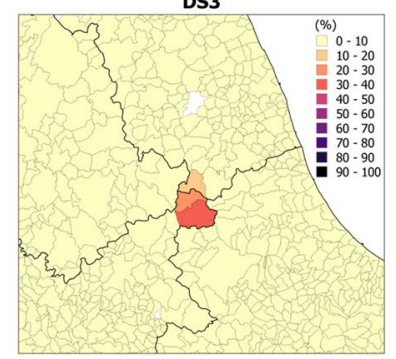

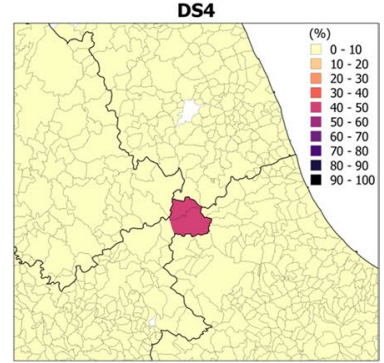

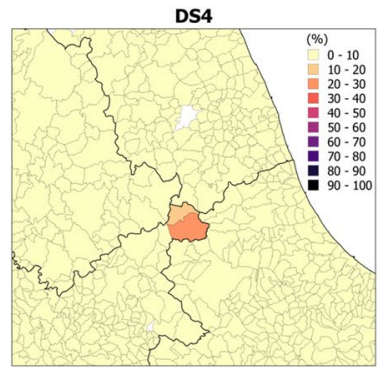

Rosti et al. (2020b) - SD

Fig. 23 Predicted damage scenarios-2016 Amatrice earthquake: \% RC buildings that reach/exceed the DSs

was not previously observed for L'Aquila 2009. This is justified by the lower standard deviation of Borzi et al. (2020b) fragility curves (which are steeper than those of Rosti et al. 2020b-SD), together with the higher PGA values reached in this earthquake.

\subsection{Comparison of consequences on building stock and population}

The consequences of the 2016 Amatrice earthquake, in terms of direct economic losses, human losses and building impact predicted by the various fragility models, are compared in Figs. 24 and 25, respectively for M and RC buildings of the municipality of Amatrice.

Regarding the comparison among risk predictions of the various models for $\mathrm{M}$ buildings, the same observations made for the L'Aquila scenario are still valid. Instead, for RC buildings, the risk figures predicted by the models of Borzi et al. (2020b) and Rosti et al. (2020b)-SD differ more than in the case of the L'Aquila scenario, with the model of Borzi et al. (2020b) being more conservative, for the above-mentioned reasons (i.e., lower standard deviation and higher PGA values).

Regarding the comparison between risk prediction and actual data, information on real data is not yet fully available for what concerns economic losses and building usability. In any case, that data would be very difficult to interpret, as the real (final) figures of economic losses and building usability include the effect of damage accumulation due to the entire seismic sequence, whereas the simulated Amatrice scenario only relates to the first event of August 24, 2016. 
(a)

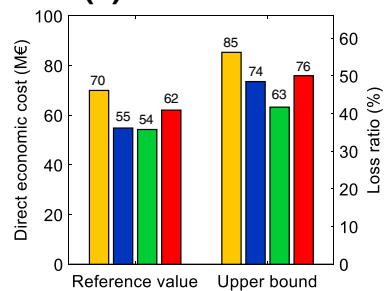

(b)

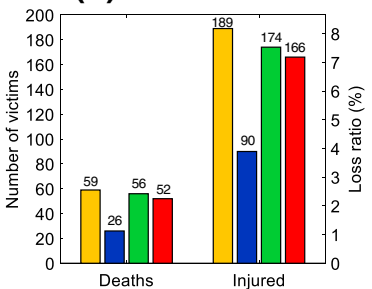

(c)

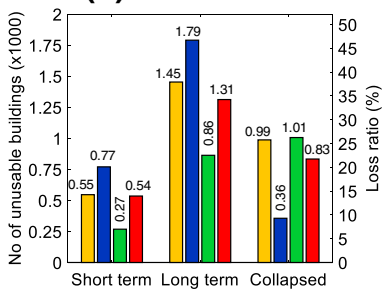

$\square$ Donà et al. (2020)

Lagomarsino et al. (2020) $\square$ Rosti et al. (2020a) $\square$ Zuccaro et al. (2020)

Fig. 24 Direct economic losses $\mathbf{a}$, human losses $\mathbf{b}$ and building impact $\mathbf{c}$ for $\mathbf{M}$ buildings in Amatrice

(a)

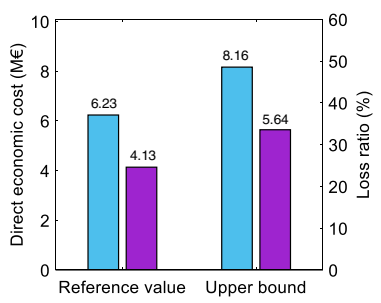

(b)

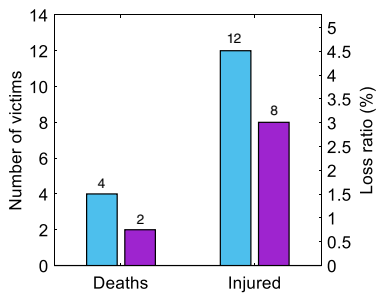

$\square$ Borzi et al. (2020b) $\square$ Rosti et al. (2020b) - SD (c)

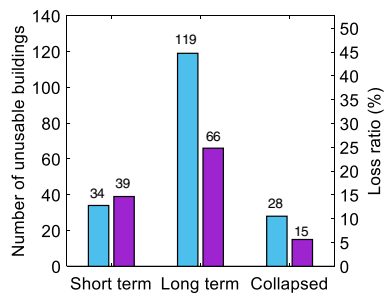

Fig. 25 Direct economic losses $\mathbf{a}$, human losses $\mathbf{b}$ and building impact $\mathbf{c}$ for RC buildings in Amatrice

With regard to the number of deaths, the predictions strongly underestimate the real data (239 deaths in the Amatrice municipality with a total number of 299 casualties in the entire affected area, Frigerio et al. 2019). However, this fact is partly justified by the unlucky concurrence of the August 24 earthquake with the very popular Amatrice festival, that used to attract many tourists and holiday-home owners. As it is known, the model used only takes residents into account, and not tourism or other variables. In Amatrice, $76 \%$ of 5257 dwellings were registered as holiday homes (Mugnano et al. 2019). Also, considering the Rieti Prefecture data (updated on September 2, 2016), 60\% of the deaths in the Accumuli and Amatrice municipalities were non-residents. If we take into account this peculiarity, the average estimates of casualties given by the various models for $\mathrm{M}$ and $\mathrm{RC}$ buildings are still sligthly lower than the actual numbers, but the figures are definitely more closely related than at first glance.

\section{National scale risk assessment}

The performance of the various fragilty models was also assessed at a national scale. To this end, the I.R.MA platform was used to produce national maps of conditional damage, unconditional damage and expected annual loss (EAL), and overall risk estimates for the entire national territory.

As regards the seismic hazard adopted in I.R.MA, which is based on the MPS04 model (Stucchi et al. 2011) as mentioned in the Introduction, a type A soil was assumed, which 
corresponds to the rock or stiff soil category according to the Italian standard for constructions (MIT 2018). This assumption is justified by the current impossibility of precisely defining the main type of soil for each municipality in Italy, and by the significant uncertainties involved in these large-scale seismic risk assessments; moreover, this choice is appropriate for the purpose of comparing the predictions of the fragility models, excluding other arbitrary assumptions.

Instead, as regards the exposure of Italian residential buildings, reference was once again made to the data of the national census (ISTAT 2001).

The fragility models adopted for the national scale assessment were exactly those validated on the seismic scenarios of L'Aquila and Amatrice described in Sect. 3 and 4, except for the Rosti et al. (2020b) model. Indeed, the Rosti et al. (2020b)-SD variant was applied for the seismic scenarios, whereas the more general Rosti et al. (2020b) model was used for the national assessment, taking into accout the presence of gravity load RC buildings in the pre-81 age, as generally found in Italy.

\subsection{Overview of conditional seismic damage}

The maps of conditional seismic damage were obtained by assuming, throughout the national territory, a seismic event with a return period $\left(T_{R}\right)$ of 475 years, which corresponds to the design earthquake associated with the life-safety limit state for residential buildings, according to the Italian standard for constructions (MIT 2018). These maps offer a damage scenario at a national level, conditioned to a specific intensity of ground shaking (of equal $T_{R}$ ), therefore they are not used for risk assessment in this work, but are particularly suitable for testing the sensitivity of the various fragility models.

Figures 26 and 27 compare these maps, obtained with the various fragility models, showing the percentages of masonry (Fig. 26) and RC (Fig. 27) buildings that reach or exceed the damage levels DS1, DS3 and DS4. A first consideration is the fact that the damage trend generally follows that of the national seismic hazard, as expected. Furthermore, the predictions of the various models are definitely comparable, despite their different derivation hypotheses. Going into detail, as regards the $\mathrm{M}$ buildings, the model of Rosti et al. (2020a) is the least conservative for the DS1 and that of Lagomarsino et al. (2021) is the least conservative for the DS3 and DS4, consistently with the previous observations on fragility curves and damage scenarios. In addition, the variation in damage predictions between DS1 and DS4 is smaller for the models of Rosti et al. (2020a) and Zuccaro et al. (2020) than the models of Donà et al. (2020) and Lagomarsino et al. (2021). This is explained by the different standard deviations of the various models discussed above; for the same reason, the distribution of the DS1 prediction is also more uniform and less intense for the models of Rosti et al. (2020a) and Zuccaro et al. (2020).

Regarding RC buildings, the models of Borzi et al. (2020b) and Rosti et al. (2020b) offer fairly similar estimates of damage at a national scale, with the model of Borzi et al. (2020b) slightly more conservative for the DS1 along the Apennine chain (where the seismic hazard is higher), as expected from comparisons of the corresponding fragility curves. In addition, $\mathrm{RC}$ buildings show lower damage predictions than $\mathrm{M}$ buildings for the same frequency of occurrence of the earthquake $\left(T_{R}=475\right.$ years). This however does not mean that RC buildings are less vulnerable than $\mathrm{M}$ buildings in general - this result should be contextualised within the national exposure information (Fig. 1). Indeed, if we very roughly consider the period before 1981 as a period of gradual transition towards more detailed and engineered constructions, we can see that $66 \%$ of RC buildings were built after 1972 (37\% in particular after 1981), whereas only $24 \%$ of M buildings were built after 1972 (11\% after 1981). 

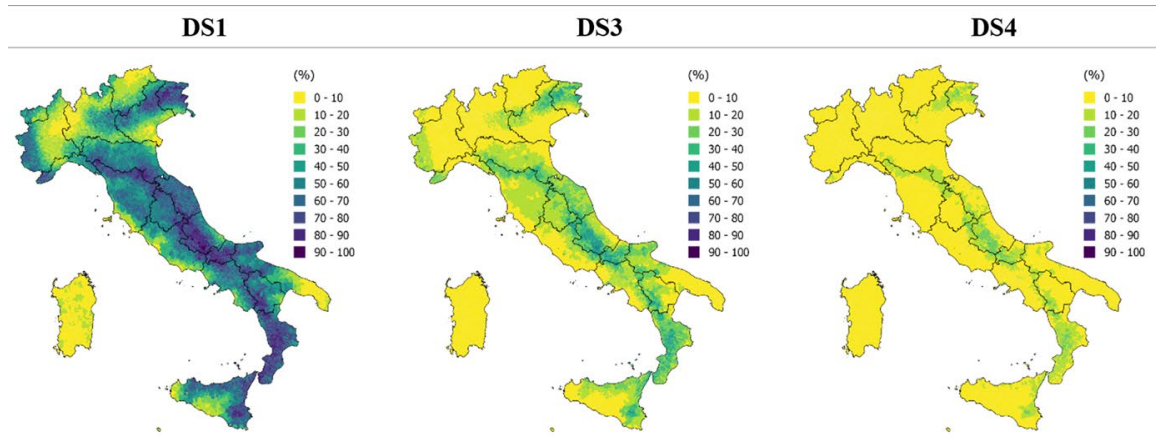

Donà et al. (2020)
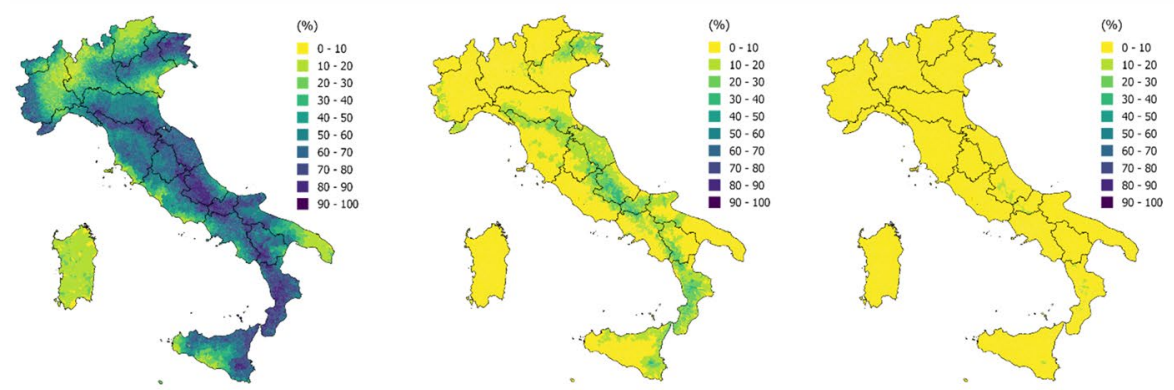

Lagomarsino et al. (2020)
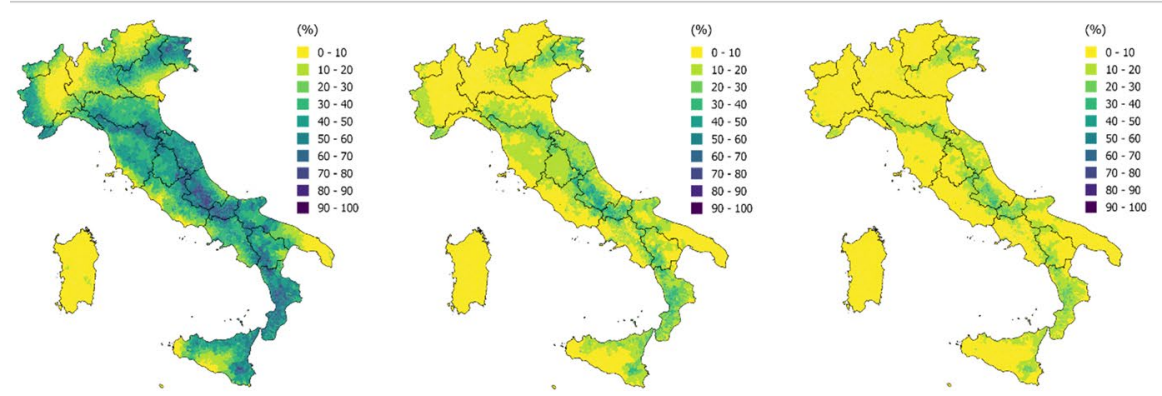

Rosti et al. (2020a)
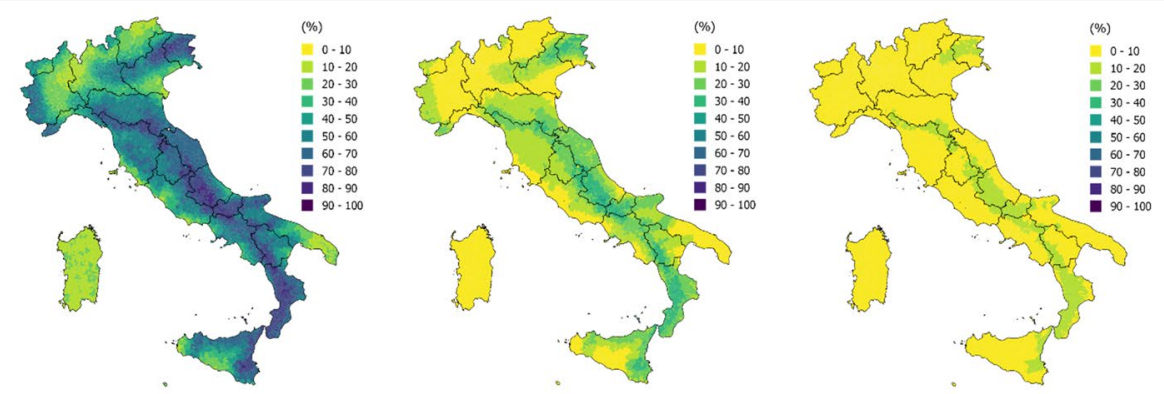

Zuccaro et al. (2020)

Fig. 26 Conditional damage maps $-T_{R}=475$ yrs, soil type A: $\%$ of M buildings exceeding DS1, DS3, DS4 


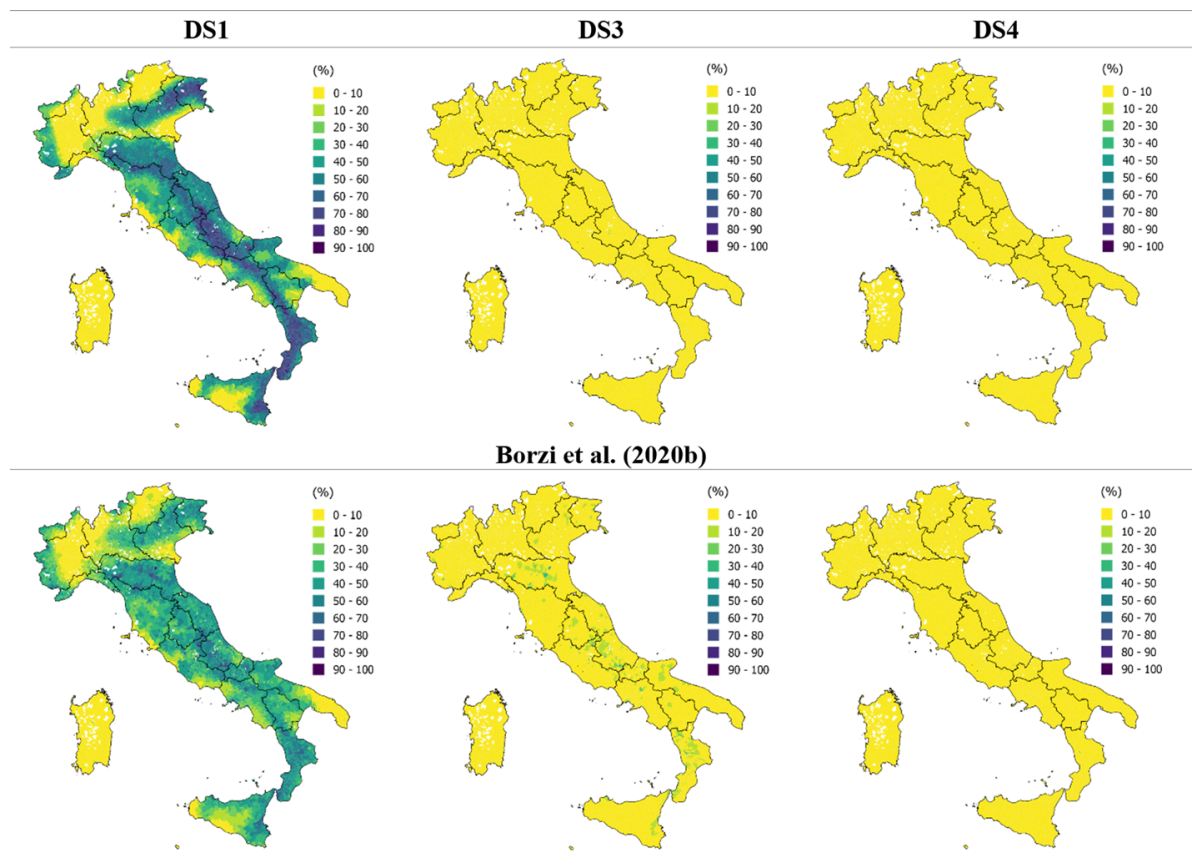

Rosti et al. (2020b)

Fig. 27 Conditional damage maps $-T_{R}=475$ yrs, soil type A: $\%$ of RC buildings exceeding DS1, DS3, DS4

A more concise representation of conditional damage is offered by the expected mean damage, which is calculated as the weighted average of the damage levels with the weights given by the respective probabilities of occurrence. The comparison of the expected mean damage maps is shown in Fig. 28, for both masonry and RC buildings. Based on this damage parameter, the models for $\mathrm{M}$ buildings of Donà et al. (2020) and Zuccaro et al. (2020) are slightly more conservative than those of Rosti et al. (2020a) and Lagomarsino et al. (2021), consistent with the previous comments. Regarding RC buildings, the most conservative model is, in general, that of Rosti et al. (2020b), which is not in agreement with what was observed when the model of Rosti et al. 2020b-SD was used. This is reasonable, considering that the model used for the national assessment also includes the higher fragility of RC buildings designed for gravity loads only. In particular, the maximum value of mean damage, reached in some municipalities of the Apennine chain and associated with an earthquake with a $T_{R}$ of $475 \mathrm{yrs}$, is about 2.5 for the $\mathrm{M}$ buildings and 1.5 for the RC buildings, where this difference is related not only to the absolute vulnerability of the various building typologies, but also to the age of the exposed built heritage, as explained above.

\subsection{Overview of unconditional seismic damage}

The maps of unconditional seismic damage were obtained by considering, in a pre-defined time window, the various intensities of earthquakes with different probabilities of occurrence. The time window of 50 years, corresponding to the nominal life of residential buildings according to the Italian standard for constructions (MIT 2018), was conventionally assumed for comparison purposes only. 


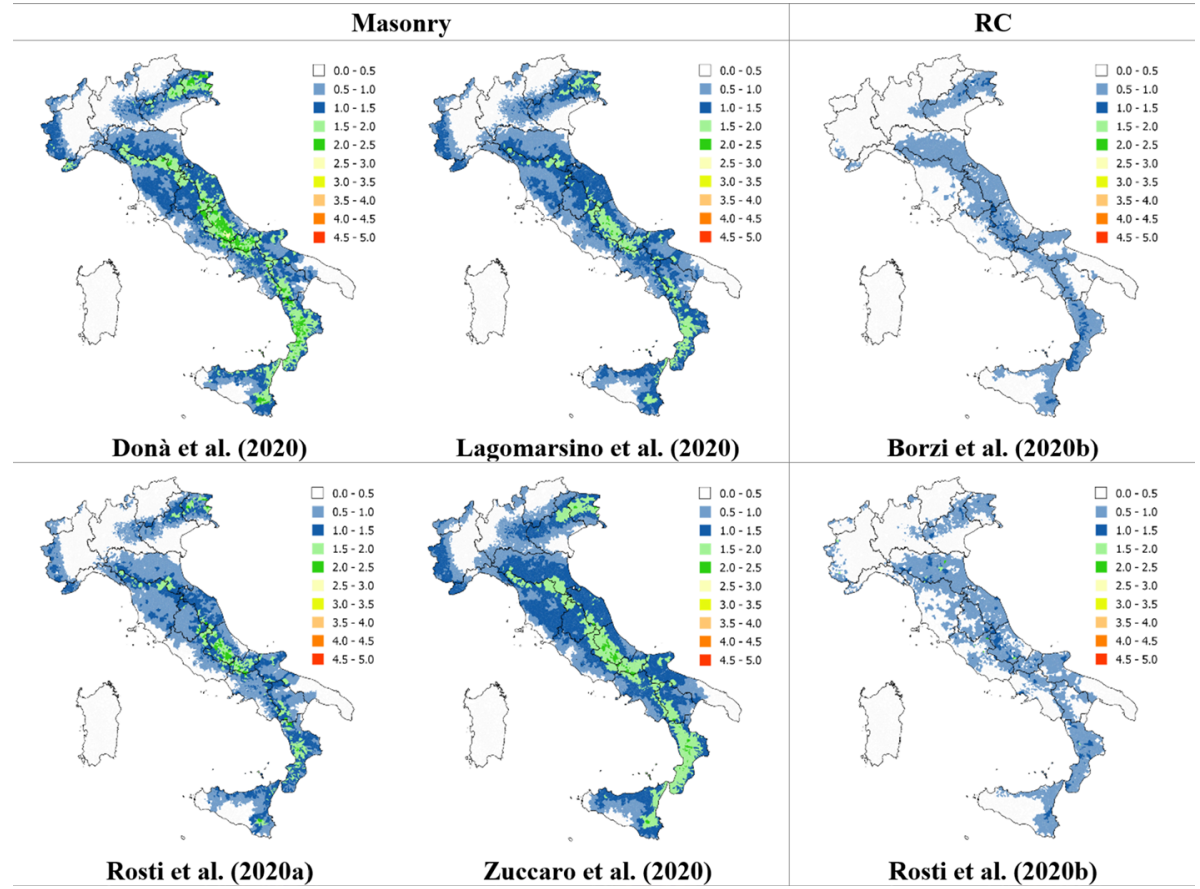

Fig. 28 Mean damage maps $-T_{R}=475$ yrs, soil type A - for M and RC buildings

Figures 29 and 30 compare these maps, obtained with the various fragility models, still showing the percentages of masonry (Fig. 29) and RC (Fig. 30) buildings that reach or exceed the damage levels DS1, DS3 and DS4. In general, the predictions of the various models are still reasonably similar. With regard to $\mathrm{M}$ buildings, as previously observed, the model of Rosti et al. (2020a) is the least conservative for the DS1, and that of Lagomarsino et al. (2021) the least conservative for the DS4. Moreover, on the basis of unconditional damage, the model of Lagomarsino et al. (2021) is also the least conservative for the DS3, and that of Zuccaro et al. (2020) appears to be the most severe for damage states up to DS3. With reference to RC buildings, the model of Rosti et al. (2020b) proves to be the most conservative, at least up to DS3. Furthermore, the M buildings' damage forecast are still more severe than the RC buildings' ones, as previously observed on the conditional damage maps.

\subsection{Overview of seismic risk estimates}

Lastly, this section presents some national risk estimates, based on the prediction of the unconditional seismic damage evaluated over a period of one year. In particular, Figs. 31 and 32 compare, respectively for masonry and RC buildings, the overall consequences of the Italian seismic risk, expected on average every year, obtained with the various fragility models and expressed in terms of direct economic losses, human losses and building impact. 

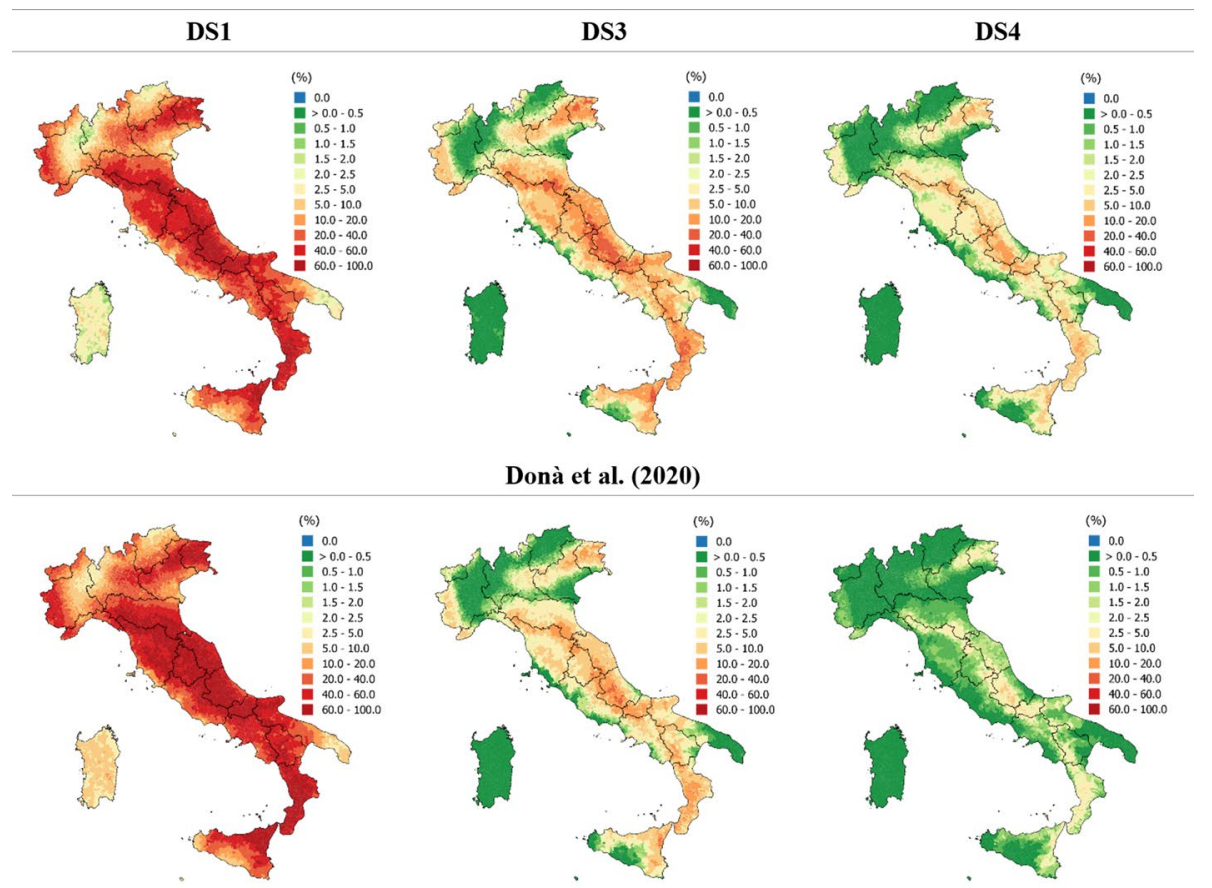

Lagomarsino et al. (2020)
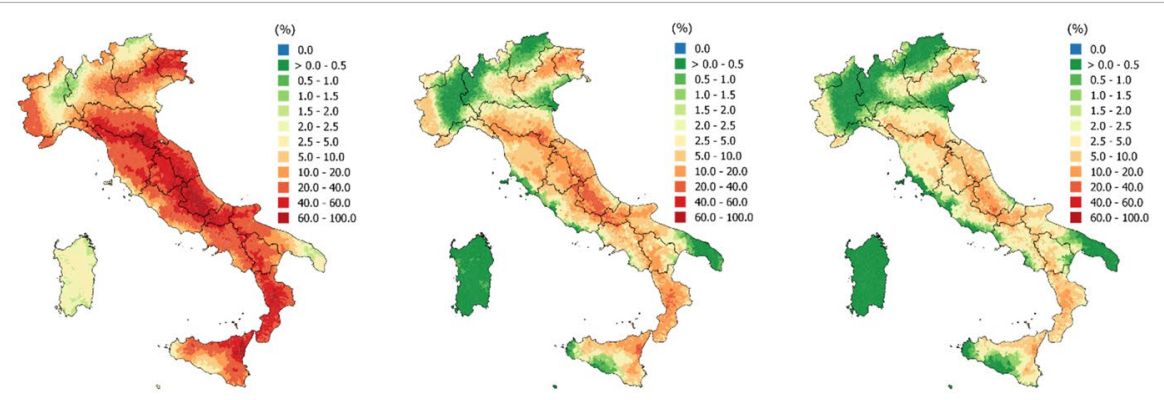

Rosti et al. (2020a)
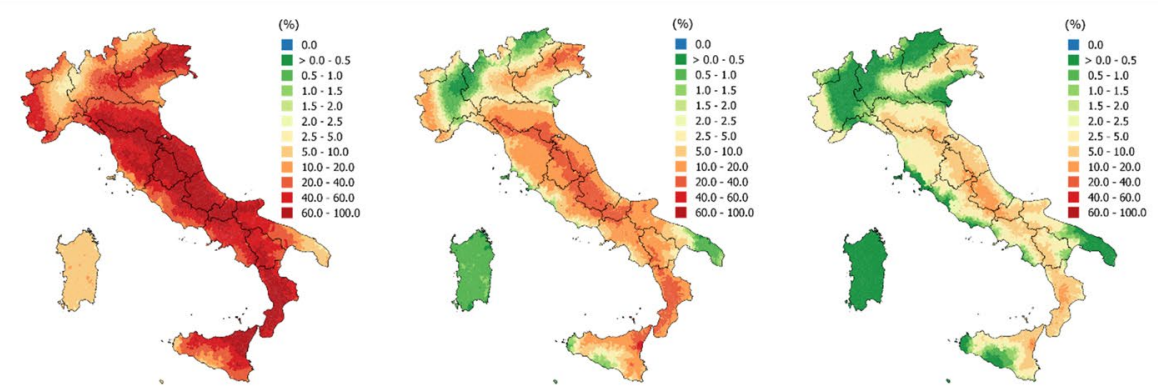

Zuccaro et al. (2020)

Fig. 29 Unconditional damage maps-50 years, soil type A: \% of M buildings exceeding DS1, DS3, DS4 

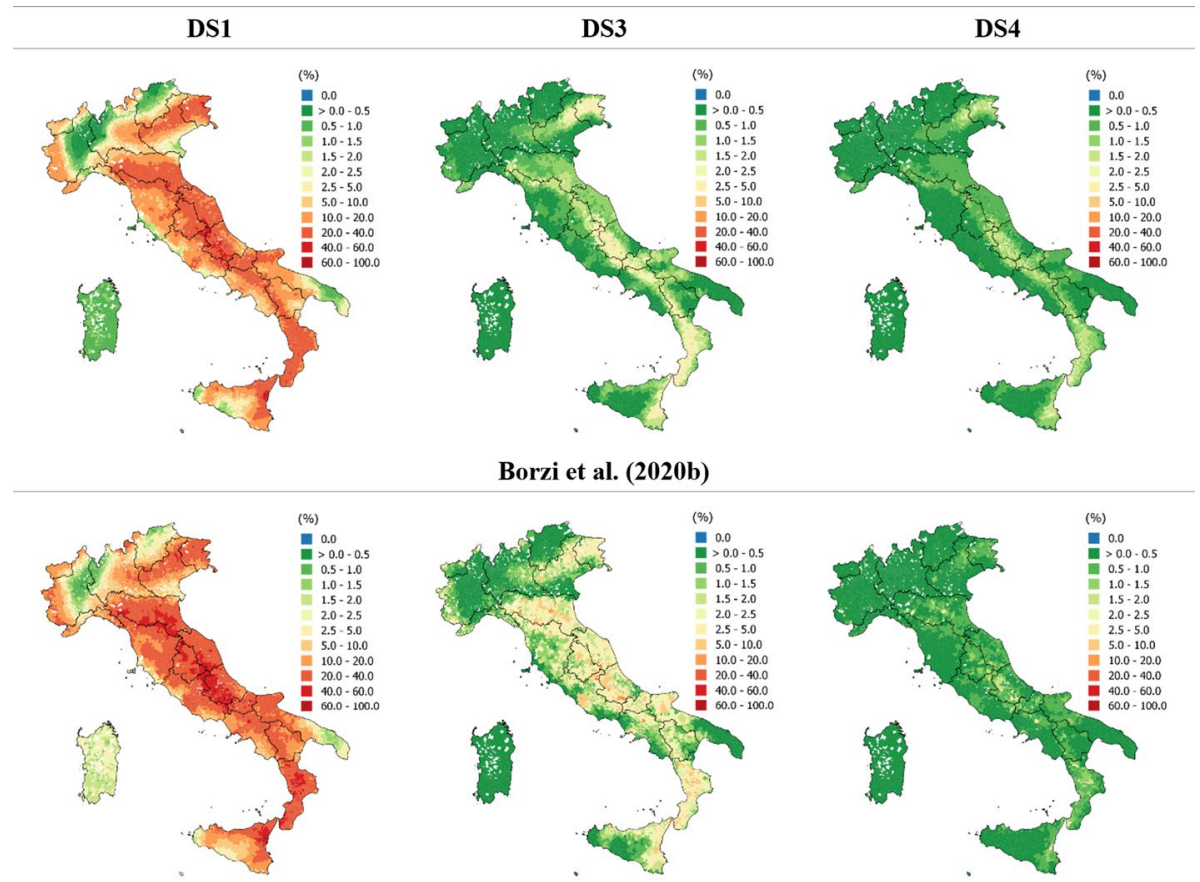

Rosti et al. (2020b)

Fig. 30 Unconditional damage maps—50 years, soil type A: \% of RC buildings exceeding DS1, DS3, DS4

Regarding M buildings, some observations made on the scenarios of L'Aquila 2009 and Amatrice 2012 still apply. In particular, the models of Rosti et al. (2020a) and Lagomarsino et al. (2021) provide the lowest cost estimates, slightly lower than those provided by Donà et al. (2020). The model of Lagomarsino et al. (2021) also gives values of victims and collapsed buildings smaller than the other models. Differently from what was observed in the scenarios, the model of Zuccaro et. al (2020) provides fairly higher estimates of seismic costs and number of unusable buildings than the other models and, in addition, the estimates of long-term unusable buildings by Lagomarsino et al. (2021) become fairly lower than those of the other models. This is justified by the analysis of unconditional damage outcomes (Fig. 29), where the model of Zuccaro et al. (2020) presents the most severe values up to DS3 and, conversely, the model of Lagomarsino et al. (2021) depicts the least severe values starting from DS3. Regarding the RC buildings, the risk estimates made by Rosti et al. (2020b) are significantly more severe than those by Borzi et al. (2020b), as expected from the corresponding unconditional damage predictions (Fig. 30). Lastly, taking into account that the damage-to-consequences models (Tables 3, 4, 5) are the same for $\mathrm{M}$ and $\mathrm{RC}$ buildings, and considering the age of the exposed buildings (see Fig. 1), the risk figures of $\mathrm{M}$ built heritage are worse than those of RC.

The economic commitment (direct funding) of the Italian State to sustain emergency management, recovery and reconstruction following the seismic events of the last 50 years amounts to approximately 211 billion euros (Dolce et al. 2020), that is about 4.2 billion euros per year. These figures do not include other losses which are difficult to be quantified, 
(a)

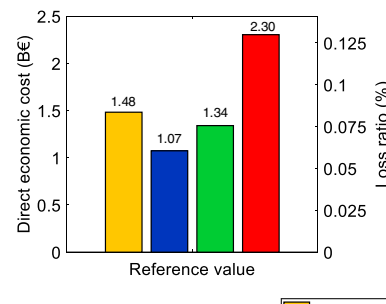

(b)

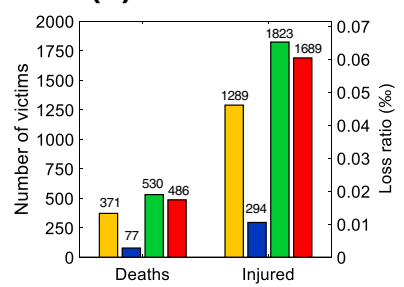

(c)

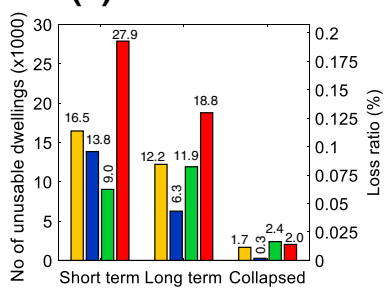

Fig. 31 Direct economic losses a, human losses $\mathbf{b}$ and building impact $\mathbf{c}$ expected in one year for $\mathbf{M}$ buildings at the national level (soil type A)

(a)

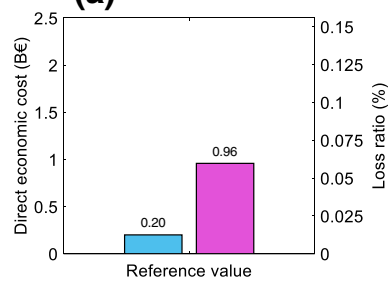

(b)

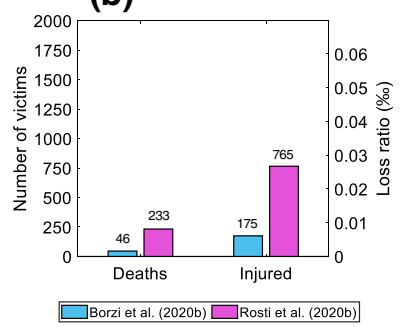

(c)

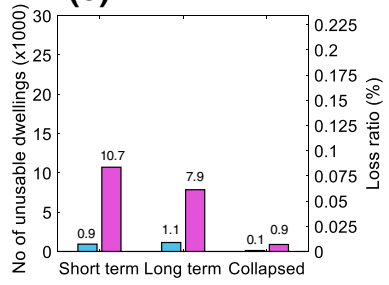

Fig. 32 Direct economic losses a, human losses $\mathbf{b}$ and building impact $\mathbf{c}$ expected in one year for RC buildings at the national level (soil type A)

such as those corresponding to victims, impairment of cultural heritage, decrease in tourism (Mazzocchi and Montini, 2001) and indirect consequences on businesses (Donà et al. 2019a; Braga et al. 2014). The economic figures predicted by the various models, overall about 2.13 billion euros, are in reasonable agreement with the above-mentioned actual costs, considering that the model outcomes refer to the repair costs of residential buildings only, and do not include other types of structures and measures that will approximately double these costs (Dolce and Di Bucci, 2017). In addition, all these simulations were conducted in the hypothesis of type A soil (rock or stiff soil), neglecting soil and site effects that could further increase these risk estimates.

Finally, Fig. 33 compares the expected annual loss (EAL), corresponding to the costs of Figs. 31a and 32a (distributed throughout the country) both for masonry and RC buildings. As can be seen, the distribution of costs does not exactly follow what previously seen for damage, as it is influenced not only by the seismic hazard and by the exposure in terms of building types, but also by the exposure in terms of absolute amount of buildings. In particular, Emilia Romagna and Sicily show the highest risk in terms of EAL, respectively for $\mathrm{M}$ and RC buildings; furthermore, the regions bordering the Tyrrhenian Sea and Veneto on the Adriatic Sea (left and right side of the maps, respectively) have higher EAL values. As regards the comparison between the various models, the trends of the regional distribution of economic loss are quite similar, with the models of Zuccaro et al. (2020)_for M buildings — and Rosti et al. (2020b)—for RC buildings_-which provide the most severe figures. 


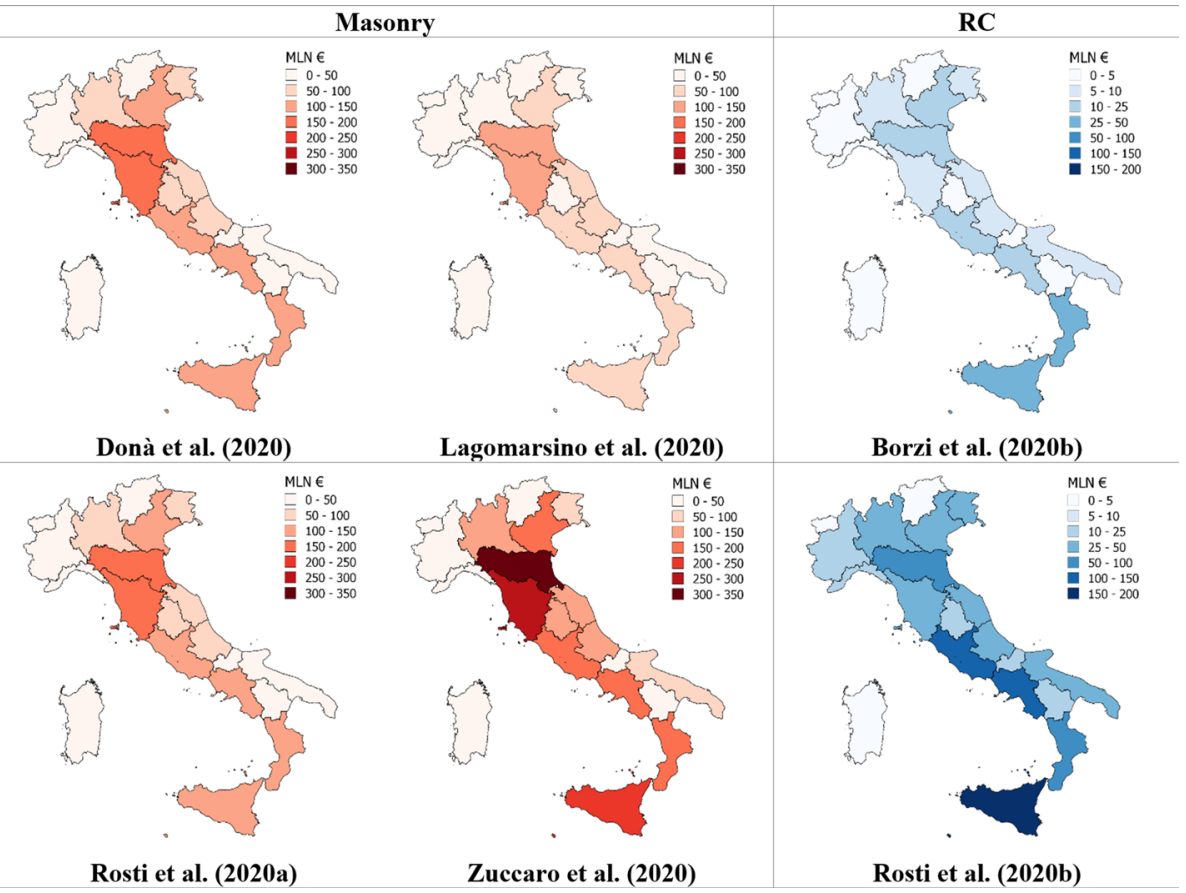

Fig. 33 Unconditional risk maps — one year (EAL), soil type A—for M and RC buildings

It is worth noting that, consistent with the aim of this study, the national seismic risk results are intentionally presented only in terms of comparison among the various models and separately for the M and RC buildings. This representation clearly highlights how the possibility of averaging risk predictions by the various models allows to derive robust risk figures (especially at the national level) and in line with the real data, levelling the most extreme estimates throughout the national territory and stressing the differences of the more uniform ones. On the other hand, as regards the further considerations on the average values of the national seismic risk estimates (in terms of direct economic losses, casualties and impact on buildings), please refer to Dolce et al. (2020), who specifically discuss these outcomes.

\section{Conclusions}

The Italian Department of Civil Protection (DPC), in compliance with the EU decision 1313/2013, released the latest National Risk Assessment at the end of 2018. As part of this activity, six research units belonging to two competence centres of the DPC collaborated under the DPC guidance to update the seismic risk maps of the Italian residential heritage. These research units developed four seismic fragility models for masonry (M) buildings and two models for reinforced concrete (RC) buildings, briefly described in this paper, which were implemented in the I.R.MA platform (Borzi et al. 2020a) by the DPC to define the national seismic risk. 
In this context, the obtained risk results were evaluated and compared to highlight the features and validate the predictive capabilities of the adopted models. In particular, predicted and observed damage scenarios and consequences on building stock and population were compared for two important and recent Italian seismic events, L'Aquila 2009 and Amatrice 2016. In addition, the seismic damage was evaluated on a national scale, considering a seismic event conditioned to a return period of 475 years (i.e., the design earthquake), and the outcomes were processed to derive national maps of mean seismic damage. Still on a national scale, maps of unconditional damage were also derived for a time window of 50 years, and unconditional risk estimates were computed with reference to one year.

The various models showed specific damage prediction trends, starting from the associated fragility curves for the various building typologies and damage states, which are justified in relation to their different derivation hypotheses, as widely discussed. In particular, the pure empirical and heuristic-empirical models (i.e., Rosti et al. 2020a; Lagomarsino et al. 2021; Zuccaro et al. 2020 for M buildings, and Rosti et al. 2020b for RC buildings) showed higher dispersion compared to mechanical ones (i.e., Donà et al. 2020; Borzi et al. 2020 b, respectively for M and RC buildings), as expected. However, the predictions of damage and consequently of risk by the various models, both at the scenario level and on a national scale, have generally proved to be reasonably comparable. The possibility of averaging the estimates of the various models allowed to derive more robust risk figures, which seem to effectively reproduce the data observed in the two recent seismic events of 2009 and 2016, and the national risk, in terms of annual costs of the earthquakes. Overall, we can state that these predictions and comparisons demonstrate the validity of the approach adopted by the DPC for the assessment of national seismic risk (DPC 2018; Dolce et al. 2020).

The predictions of damage and risk on a national scale highlight the higher vulnerability of the residential masonry heritage compared to RC. This fact is due not only to the intrinsic vulnerability of the $\mathrm{M}$ and $\mathrm{RC}$ building macro-typologies, but also to the larger amount of non-engineered $\mathrm{M}$ buildings. The risk figures obtained from the damage estimates were calculated with the same simplified damage-to-impact models for both $\mathrm{M}$ and RC buildings. This is clearly a limitation of this study and such models should be refined with specific calibrations on the various typologies, in order to rationally evaluate the impact of the earthquake on the various building types, and thus obtain more reliable risk predictions.

The final outcome of this work is the average expected annual loss (EAL) distributed throughout the country. Obviously, these maps hightlighted higher EAL values associated not only with higher seismic hazard, but also with significant exposure at a regional level. Hence, these maps appear to be a very useful tool for seismic risk management policies at national level, allowing to effectively calibrate future mitigation strategies on the various territorial contexts. Further observations about the national average seismic risk estimates, deriving from the fragility models compared in this study, can be found in Dolce et al. (2020), also in relation to other evaluation methodologies and predictions currently available.

Lastly, although the obtained results are encouraging, the awareness of the complexity of these assessments, of the many uncertainties involved, and therefore also of the great potential for improvement, asks for further investigations and discussions (within a broad scientific audience) in order to obtain increasingly refined, reliable and shared risk information on a wide territorial scale. In particular, future studies will be aimed at: (1) refining the macro-typological classification, with particular attention to geographical and demographic representativeness, in order to provide a possible regionalisation of the proposed 
fragility models, (2) improving the knowledge of the seismic hazard, introducing the prevailing type of soil, up to the municipal level, in the I.R.MA platform, (3) calibrating damage-to-impact models specifically for the various building typologies, in order to derive more reliable risk figures starting from damage estimates, (4) improving the current risk estimates by introducing the possible mitigation effect due to the strengthening interventions carried out in the aftermath of significant Italian earthquakes. This complex activity is currently underway to provide future updates of the national seismic risk (Masi et al. 2021), involving a broader scientific community.

Acknowledgements Special thanks are due to the Italian Civil Protection Department and ReLUIS-for having motivated the realization of this work and for coordinating the Work Group on the seismic vulnerability assessment of the Italian residential building heritage. All researchers and collaborators working in each Research Unit are kindly acknowledged and in particular: Veronica Follador and Pietro Carpanese for the Padova RU; Guido Magenes and Andrea Penna for the Pavia RU; Daria Ottonelli and Sabrina Vignolo for the Genoa RU; Gerardo Mario Verderame, Marco Di Ludovico and Maria Polese for the Naples Federico II RU; Giulio Zuccaro and Francesco Cacace for the PLINIVS research Unit. The results were achieved in the national research project ReLUIS-DPC 2018 (www.reluis.it), supported by the Italian Civil Protection Department.

Funding Open access funding provided by Università degli Studi di Padova within the CRUI-CARE Agreement.

\section{Declarations}

Conflict of interest The authors have no conflicts of interest to declare that are relevant to the content of this article.

Open Access This article is licensed under a Creative Commons Attribution 4.0 International License, which permits use, sharing, adaptation, distribution and reproduction in any medium or format, as long as you give appropriate credit to the original author(s) and the source, provide a link to the Creative Commons licence, and indicate if changes were made. The images or other third party material in this article are included in the article's Creative Commons licence, unless indicated otherwise in a credit line to the material. If material is not included in the article's Creative Commons licence and your intended use is not permitted by statutory regulation or exceeds the permitted use, you will need to obtain permission directly from the copyright holder. To view a copy of this licence, visit http://creativecommons.org/licenses/by/4.0/.

\section{References}

Alexander DE (2011) Mortality and morbidity risk in the L'Aquila, Italy Earthquake of 6 April 2009 and lessons to be learned. In Spence, So, Scawthorn (eds) Human casualties in earthquakes - progress in modelling and mitigation, advances in natural and technological hazards research, vol 29, pp 185-198. Springer, Berlin. https://doi.org/10.1007/978-90-481-9455-1

Alexander D, Magni M (2013) Mortality in the L'Aquila (Central Italy) Earthquake of 6 April 2009. PLOS Curr Disasters. https://doi.org/10.1371/50585b8e6efd1

Baggio C, Bernardini A, Colozza R, Coppari S, Corazza L, Della Bella M, Di Pasquale G, Dolce M, Goretti A, Martinelli A, Orsini G, Papa F, Zuccaro G (2007) Field manual for post-earthquake damage and safety assessment and short term countermeasures (AeDES). (Pinto A, Taucer F eds), Translation from Italian: Goretti A, Rota M, JRC Scientific and Technical Reports, EUR 22868 EN-2007

Borzi B, Pinho R, Crowley H (2008) Simplified pushover-based vulnerability analysis for large-scale assessment of RC buildings. Eng Struct 30:804-820. https://doi.org/10.1016/j.engstruct.2007.05.021

Borzi B, Onida M, Faravelli M, Polli D, Pagano M, Quaroni D, Cantoni A, Speranza E, Moroni C (2020a) IRMA platform for the calculation of damages and risks of Italian residential buildings. Bull Earthq Eng. https://doi.org/10.1007/s10518-020-00924-x 
Borzi B, Faravelli M, Di Meo A (2020b) Application of the SP-BELA methodology to RC residential buildings in Italy to produce seismic risk maps for the national risk assessment. Bull Earthq Eng. https://doi. org/10.1007/s10518-020-00953-6

Braga F, Gigliotti R, Monti G, Morelli F, Nuti C, Salvatore W, Vanzi I (2014) Speedup of post earthquake community recovery: The case of precast industrial buildings after the Emilia 2012 earthquake. Bull Earthq Eng 12(5):2405-2418

Cacace F, Zuccaro G, De Gregorio D, Perelli FL (2018) Building Inventory at National scale by evaluation of seismic vulnerability classes distribution based on Census data analysis: BINC procedure. Int J Disaster Risk Reduct 28:384-393

CIAM1563 - Collegio degli Ingegneri e Architetti di Milano (2019) Prezzi Tipologie Edilizie 2019. Quine DEI Tipografia del Genio Civile, ISBN: 9788831284035 (in Italian)

Coburn AW, Spence R (1992) Earthquake Protection: John Wiley and Sons Ltd, England, p 355

Crowley H, Despotaki V, Rodrigues D, Silva V, Toma-Danila D, Riga E, Karatzetzou A, Zugic Z, Sousa L, Ozcebe S, Gamba P (2020) Exposure model for European seismic risk assessment. Earthq Spectra. https://doi.org/10.1177/8755293020919429

D’Alpaos C, Bragolusi P (2020) The market price premium for buildings seismic retrofitting. Sustainability 12:8791. https://doi.org/10.3390/su12218791

Del Gaudio C, De Martino G, Di Ludovico M, Manfredi G, Prota A, Ricci P, Verderame GM (2017) Empirical fragility curves from damage data on RC buildings after the 2009 L'Aquila earthquake. Bull Earthq Eng 15(4):1425-1450

Di Ludovico M, Prota A, Moroni C, Manfredi G, Dolce M (2017a) Reconstruction process of damaged residential buildings outside historical centres after the L'Aquila earthquake: part I - "light damage" reconstruction. Bull Earthq Eng 15:667-692. https://doi.org/10.1007/s10518-016-9877-8

Di Ludovico M, Prota A, Moroni C, Manfredi G, Dolce M (2017b) Reconstruction process of damaged residential buildings outside historical centres after the L'Aquila earthquake: part II - "heavy damage" reconstruction. Bull Earthq Eng 15:693-729. https://doi.org/10.1007/s10518-016-9979-3

Dolce M, Di Bucci D (2017) Comparing recent Italian earthquakes. Bull Earthq Eng 15:497-533. https:// doi.org/10.1007/s10518-015-9773-7

Dolce M, Di Bucci D (2018) The 2016-2017 Central apennines seismic sequence: analogies and differences with recent italian earthquakes. In: Pitilakis K (ed) Recent advances in earthquake engineering in Europe. ECEE 2018. Geotechnical, geological and earthquake engineering, vol 46. Springer, Cham. https://doi.org/10.1007/978-3-319-75741-4_26

Dolce M, Speranza E, Giordano F, Borzi B, Bocchi F, Conte C, Di Meo A, Faravelli M, Pascale V (2017) Da.D.O. - A web-based tool for analyzing and comparing post-earthquake damage database relevant to national seismic events since 1976. Proceedings of the 17th Italian Conf on Earthq Eng ANIDIS. Pistoia, Italy. https://www.researchgate.net/publication/320323419_DaDO_-_A_webbased_tool_for_ analyzing_and_comparing_postearthquake_damage_database_relevant_to_national_seismic_events_ since_1976_-_DaDO_-_Uno_strumento_per_la_consultazione_e_la_comparazione_del_dan

Dolce M, Speranza E, Giordano F, Borzi B, Bocchi F, Conte C, Di Meo A, Faravelli M, Pascale V (2019) Observed damage database of past Italian earthquakes: the Da.D.O WebGIS. Boll Geofis Teor Appl 60(2):141-164

Dolce M, Prota A, Borzi B, da Porto F, Lagomarsino S, Magenes G, Moroni C, Penna A, Polese M, Speranza E, Verderame GM, Zuccaro G (2020) Seismic risk assessment of residential buildings in Italy. Bull Earthq Eng. https://doi.org/10.1007/s10518-020-01009-5

Donà M, Bizzaro L, Carturan F, da Porto F (2019a) Effects of business recovery strategies on seismic risk and cost-effectiveness of structural retrofitting for business enterprises. Earthq Spectra 35(4):1795-1819

Donà M, Carpanese P, Follador V, da Porto F (2019b) Derivation of mechanical fragility curves for macrotypologies of Italian masonry buildings. In Proceedings of 7th ECCOMAS thematic conference on computational methods in structural dynamics and earthquake engineering, Crete, June 24-26, 2019, $1691-1706$

Donà M, Carpanese P, Follador V, Sbrogiò L, da Porto F (2020) Mechanics-based fragility curves for Italian residential URM buildings. Bull Earthq Eng. https://doi.org/10.1007/s10518-020-00928-7

Eleftheriadou AK, Karabinis AI (2013) Evaluation of damage probability matrices from observational seismic damage data. Earthq Struct 4(3):299-324

Eucentre (2018) I.R.MA. (Italian Risk Maps), Manuale di navigazione utente. (in Italian)

European Parliament and Council of the European Union (2013) Decision no. 1313/2013/EU of 17 December 2013. Official Journal of the European Union, L 347/924, 20/12/2013 
Faccioli E, Cauzzi C (2006) Macroseismic intensities for seismic scenarios estimated from instrumentally based correlations. In: Proc. of the First European Conference on Earthquake Engineering and Seismology, Ginevra, September 3-8, 2006, CD-ROM

Frigerio I, Zanini F, Mattavelli M, De Amicis M (2019) Understanding the interacting factors that influence social vulnerability: a case study of the 2016 central Italy earthquake. Disasters 43:867-890. https:// doi.org/10.1111/disa. 12403

Goretti A, Di Pasquale G (2004) Building inspection and damage data for the 2002 Molise, Italy, earthquake. Earthq Spectra 20(S1):S167-S190

Grünthal G (1998) European Macroseismic Scale. Chaiers du Centre Européen de Géodynamique et de Séismologie, vol. 15 Luxembourg

National Institute of Geophysics and Volcanology, INGV: http://www.ingv.it/it/

Italian Civil Protection Department of the Presidency of the Council of Ministers - ICPD (2018) National risk assessment - Overview of the potential major disasters in Italy: seismic, volcanic, tsunami, hydrogeological/hydraulic and extreme weather, droughts and forest fire risks, pp. 1 - 137

Italian National Institute of Statistics, ISTAT (2001, 2011) Website and data warehouse: https://www.istat.it/ it/censimenti-permanenti/censimenti-precedenti/popolazione-e-abitazioni

Karababa FS, Pomonis A (2011) Damage data analysis and vulnerability estimation following the August 14, 2003 Lefkada Island, Greece, Earthquake. Bull Earthq Eng 9:1015-1046

Lagomarsino S, Cattari S (2014) Fragility functions of masonry buildings, Chapter 5 in K. Pitilakis, H. Crowley, A.M. Kaynia (eds.), SYNER-G: Typology definition and fragility functions for physical elements at seismic risk, vol 27, pp 111-156, Springer, Berlin

Lagomarsino S, Giovinazzi S (2006) Macroseismic and mechanical models for the vulnerability assessment of current buildings. Bull Earthq Eng 4(4):445-463

Lagomarsino S, Cattari S, Ottonelli D (2021) The heuristic vulnerability model: fragility curves for masonry buildings. Bull Earthq Eng. https://doi.org/10.1007/s10518-021-01063-7

Legislative Decree no.1 of 2 January (2018) Codice di Protezione Civile ("Code of Civil Protection"). GU no. 17 of 22 January 2018, Italy (in Italian)

Margottini C, Molin D, Serva L (1992) Intensity versus ground motion: A new approach using Italian data. Eng Geol 33(1):45-58

Masi A, Lagomarsino S, Dolce M, Manfredi V, Ottonelli D (2021) Towards the updated Italian seismic risk assessment: exposure and vulnerability modelling. Bull Earthq Eng. https://doi.org/10.1007/ s10518-021-01065-5

Mazzocchi M, Montini A (2001) Earthquake effects on tourism in central Italy. Ann Tour Res 28(4):1031-1046

MIT (Italian Ministry of Infrastructure and Transport). 2018. Update of the "Technical Standards for Constructions” 2018. DM 2018/01/17, “S.O. No. 8 alla G.U. del 20 Febbraio 2018, No. 32”, Rome, Italy: MIT (in Italian)

Mugnano S, Carnelli F, Zizzari S (2019) The recovery strategy of second homeowners and tourists after a disaster: insights from the 2016 central Italy earthquakes. In: Farabollini P, Lugeri FR, Mugnano S (eds), Earthquake risk perception, communication and mitigation strategies across Europe, Il Sileno Edizioni, Geographies of the Anthropocene book series, Rende, vol 2, pp 267-284

Pagani M, Monelli D, Weatherill G, Danciu L, Crowley H, Silva V, Henshaw P, Butler L, Nastasi M, Panzeri L, Simionato M (2014) OpenQuake engine: An open hazard (and risk) software for the global earthquake model. Seismol Res Lett 85(3):692-702

Perelli FL, De Gregorio D, Cacace F, Zuccaro G (2019) Empirical vulnerability curves for Italian masonry buildings. In Proceedings of 7th ECCOMAS Thematic Conference on Computational Methods in Structural Dynamics and Earthquake Engineering, Crete, June 24-26, 2019, pp 1745-1758

Prefettura di Rieti (2016) Sisma del 24 agosto 2016, elenco delle vittime riconosciute (aggiornamento al 2 settembre 2016 ore 13,00 )

Riga E, Karatzetzou A, Apostolaki S, Crowley H, Pitilakis K (2021) Verification of seismic risk models using observed damages from past earthquake events. Bull Earthq Eng. https://doi.org/10.1007/ s10518-020-01017-5

Rossetto T, Peiris N, Alarcon JE, So E, Sargeant S, Free M, Sword-Daniels V, Del Re D, Libberton C, Verrucci E, Sammonds P, Faure Walker J (2011) Field observations from the Aquila, Italy earthquake of April 6, 2009. Bull Earthquake Eng 9:11-37. https://doi.org/10.1007/s10518-010-9221-7

Rossetto T, Ioannou I, Grant DN (2013) Existing empirical vulnerability and fragility functions: Compendium and guide for selection. GEM Technical Report 2013-X, GEM Foundation, Pavia, Italy

Rosti A, Rota M, Penna A (2018) Damage classification and derivation of damage probability matrices from L'Aquila (2009) post-earthquake survey data. Bull Earthq Eng 16(9):3687-3720 
Rosti A, Rota M, Penna A (2020a) Empirical fragility curves for Italian URM buildings. Bull Earthq Eng. https://doi.org/10.1007/s10518-020-00845-9

Rosti A, Del Gaudio C, Rota M, Ricci P, Di Ludovico M, Penna A, Verderame GM (2020b) Empirical fragility curves for Italian residential RC buildings. Bull Earthq Eng. https://doi.org/10.1007/ s10518-020-00971-4

Rota M, Penna A, Strobbia CL (2008) Processing Italian damage data to derive typological fragility curves. Soil Dyn Earthq Eng 28(10):933-947

United Nations International Strategy for Disaster Reduction (2015) Sendai Framework for Disaster Risk Reduction 2015-2030. https://www.unisdr.org/files/43291_sendaiframeworkfordrren.pdf

Silva V, Amo-Oduro D, Calderon A, et al. (2018) Global Earthquake Model (GEM). Seismic Risk Map (version 2018.1). https://doi.org/10.13117/GEM-GLOBAL-SEISMIC-RISK-MAP-2018.1

Silva V, Amo-Oduro D, Calderon A, Costa C, Dabbeek J, Despotaki V, Martins L, Pagani M, Rao A, Simionato M, Viganò D, Yepes-Estrada C, Acevedo A, Crowley H, Horspool N, Jaiswal K, Journeay M, Pittore M (2020) Development of a global seismic risk model. Earthq Spectra. https://doi.org/10.1177/ 8755293019899953

Spence R, So E, Jenkins S, Coburn A, Ruffle S (2011) A global earthquake building damage and casualty database. In Spence, So, Scawthorn (eds.), Human casualties in earthquakes - progress in modelling and mitigation, advances in natural and technological hazards research, vol. 29, pp 65-82. Springer, Berlin. https://doi.org/10.1007/978-90-481-9455-1

Stucchi M, Akinci A, Faccioli E, Gasperini P, Malagnini L, Meletti C, Montaldo V, Valensise G (2004) Mappa di Pericolosità sismica del territorio Nazionale. http://zonesismiche.mi.ingv.it/documenti/rappo rto_conclusivo.pdf (in italian)

Stucchi M, Meletti C, Montaldo V, Crowley H, Calvi GM, Boschi E (2011) Seismic hazard assessment (2003-2009) for the Italian building code. Bull Seismol Soc Am 101:1885-1911

Valluzzi MR (2009) User Manual of Vulnus_4.0, original program by Bernardini A, Gori R, Modena C, Vb version edited by Valluzzi MR, with contributions by Benincà G, Barbetta E, Munari M (in Italian)

Zuccaro G (2004) Inventory and vulnerability of the residential buildings in Italy. Risk maps and socioeconomic losses. Final Report SAVE Project, Task 1. GNDT, Rome

Zuccaro G, Cacace F (2011) Seismic casualty evaluation: the Italian model, an application to the L'Aquila 2009 event. In Spence, So, Scawthorn (eds.), Human casualties in earthquakes - progress in modelling and mitigation, advances in natural and technological hazards research, vol 29, pp 171-184. springer, Berlin. https://doi.org/10.1007/978-90-481-9455-1

Zuccaro G, Cacace F (2015) Seismic vulnerability assessment based on typological characteristics. First level procedure S.A.V.E.. Soil Dyn Earthquake Eng, pp 262-269

Zuccaro G, Perelli FL, De Gregorio D, Cacace F (2020) Empirical vulnerability curves for Italian mansory buildings: evolution of vulnerability model from the DPM to curves as a function of accelertion. Bull Earthq Eng. https://doi.org/10.1007/s10518-020-00954-5

Publisher's Note Springer Nature remains neutral with regard to jurisdictional claims in published maps and institutional affiliations.

\section{Authors and Affiliations}

\section{Francesca da Porto ${ }^{1}$ - Marco Donà ${ }^{1}$ (D) - Annalisa Rosti ${ }^{2} \cdot$ Maria Rota $^{3}$. \\ Sergio Lagomarsino ${ }^{4}$. Serena Cattari ${ }^{4}$ - Barbara Borzi $i^{3} \cdot$ Mauro Onida $^{3}$. Daniela De Gregorio ${ }^{5}$. Francesca Linda Perelli ${ }^{5}$. Carlo Del Gaudio ${ }^{6}$. Paolo Ricci ${ }^{6}$. Elena Speranza ${ }^{7}$}

1 Department of Geosciences, University of Padua, via Gradenigo 6, 35131 Padova, Italy

2 Department of Civil Engineering and Architecture, University of Pavia, via Ferrata 3, 27100 Pavia, Italy

3 EUCENTRE Foundation, via Ferrata 1, 27100 Pavia, Italy

4 Department of Civil, Chemical and Environmental Engineering, University of Genoa, via Montallegro 1, 16145 Genova, Italy 
5 PLINIVS-LUPT Study Centre, University of Naples Federico II, Via Toledo 402, 80134 Napoli, Italy

6 Department of Structures for Engineering and Architecture, University of Naples Federico II, Via Claudio 21, 80125 Napoli, Italy

7 Department of Civil Protection, Presidency of the Council of Ministers, Via Ulpiano 11, 00193 Roma, Italy 